\title{
Medial Lemniscal and Spinal Projections to the Macaque Thalamus: An Electron Microscopic Study of Differing GABAergic Circuitry Serving Thalamic Somatosensory Mechanisms
}

\author{
Henry J. Ralston III and Diane Daly Ralston \\ Department of Anatomy, W. M. Keck Foundation Center for Integrative Neuroscience, University of California, San \\ Francisco, California, 94143-0452
}

The synaptic relationships formed by medial lemniscal (ML) or spinothalamic tract (STT) axon terminals with neurons of the somatosensory ventroposterolateral thalamic nucleus of the macaque monkey have been examined quantitatively by electron microscopy. ML and STT axons were labeled by the anterograde axon transport of WGA-HRP following injection of the tracer into the contralateral dorsal column nuclei, or the dorsal horn of the spinal cord, respectively. Thalamic tissue was histochemically reacted for the presence of HRP. Serial thin sections were stained with a gold-labeled antibody to GABA, to determine which neuronal elements exhibited GABA immunoreactivity (GABA-ir). Serially sectioned thalamic structures were recorded in electron micrographs and reconstructed in three dimensions by computer.

Individual ML axon terminals form multiple synaptic contacts with segments of the proximal dendritic trees of thalamocortical relay neurons and also synapse upon the dendritic appendages of GABA-ir interneurons (local circuit neurons). These GABA-ir dendritic appendages contain synaptic vesicles and are presynaptic (presynaptic dendrites) to the same segments of relay neuron dendrites that receive ML contacts. When analyzed in serial sections and reconstructed by computer, the ML terminals form triadic relationships (ML, GABA appendage, and relay neuron dendrite) or more complex glomerular arrangements involving multiple appendages, all of which then contact the relay neuron dendritic segment. In contrast, multiple STT terminals make synaptic contacts along segments of projection neuron dendrites and are usually the only type of profile to contact that segment of dendrite. More than $85 \%$ of the spinal afferents form simple axodendritic synapses with relay cells and do not contact GABA-ir appendages.

The thalamic synaptic relationships of ML terminals are fundamentally different from those formed by the STT. Because STT neurons predominately transmit information about noxious stimuli, the simple axodendritic circuitry of the ma-

\footnotetext{
Received Apr. 28, 1993; revised Oct. 1, 1993; accepted Oct. 19, 1993.

We thank Ms. Antonia M. Milroy for her expertise in preparing the experimental material for electron microscopy and Ms. Sandra Canchola for her expert assistance in the preparation of the light microscopic material and the photographic platcs. This work was supported by NS 23347 and NS 21445 from the National Institutes of Health.

Correspondence should be addressed to Henry J. Ralston III, Department of Anatomy, University of California, San Francisco, CA 94143-0452.

Copyright (C) 1994 Society for Neuroscience $0270-6474 / 94 / 142485-18 \$ 05.00 / 0$
}

jority of these spinal afferents suggests that the transmission of noxious information is probably not subject to GABAergic modulation by thalamic interneurons, in contrast to the GABAergic processing of non-noxious information carried by the ML afferents. The differences in the GABAergic circuits of the thalamus that mediate ML and STT afferent information are believed to underlie differential somatosensory processing in the forebrain. We suggest that changes in thalamic GABAergic dendritic appendages and GABA receptors following CNS injury may play a role in the genesis of some central pain states.

IKey words: thalamus, somatosensory, monkey, GABA, medial lemniscus, spinothalamic tract, inhibition, interneuron, pain]

Several studies of the neuronal and synaptic organization of the thalamus of monkey and of cat have revealed a complex circuitry for processing afferent information (reviewed in Ralston, 1983, 1991; Jones, 1985). Thalamic nuclei contain two neuronal cell types: (1) the thalamocortical relay cell, usually about 20 $40 \mu \mathrm{m}$ in cell body diameter, which projects to functionally related regions of the cerebral cortex and which constitutes approximately $75-90 \%$ of the total complement of neurons, and (2) the interneuron (local circuit neuron), which represents approximately $10-25 \%$ of the total neuronal population (Le Vay, 1971; Hamori and Pasik, 1983) and which exhibits GABA imInunoreactivity (GABA-ir; Spreafico et al., 1983). When stained by the Golgi method (Guillery, 1966; Szentagothai et al., 1966) or labeled by the intracellular iontophoresis of HRP (Hamos et al., 1985; Yen et al., 1985; Ohara et al., 1987; Wilson, 1989) the interneurons have been shown to be morphologically distinct from relay cells, being approximately $10-15 \mu \mathrm{m}$ in cell body diameter and to possess complex dendritic appendages. The thalamocortical relay cells lack these dendritic appendages.

The first electron microscopic study of the primate thalamus (LGN; Colonnier and Guillery, 1964) showed that the retinal afferents contained rounded synaptic vesicles and were the largest synaptic profile present (designated RL profiles). The RL retinal terminals not only contacted the dendrites of relay cells, but were also presynaptic to vesicle-containing profiles that, in turn, contacted the relay cell dendrites to form a triadic synaptic relationship. These postsynaptic vesicle-containing profiles were subsequently shown to be the dendritic appendages of interneurons (Ralston and Herman, 1969; Ralston, 1971), to be GABA-ir (Hendrickson et al., 1983; Ohara et al., 1989; KultasIlinsky and Ilinsky, 1991), and to be presynaptic, and have thus 
been called presynaptic dendrites. In some cases the retinal (cat LGN; Rapisardi and Miles, 1984) or lemniscal (cat ventroposterolateral nucleus, VPL; Ralston, 1969; monkey VPL; Ralston, 1991) afferent axon terminals form complex synaptic structures (glomeruli), in which the afferent synapses upon a relay cell dendritic shaft and multiple interncuronal dendritic appendages simultaneously. The vesicle-filled appendages, in turn, contact the relay cell dendrite. These relationships between afferent, relay cell, and GABA-ir appendages presumably serve a fundamental aspect of information transfer in the thalamus, in which the afferent axon transmits an excitatory message to the relay cell and to the GABAergic appendages, resulting in feedforward GABAergic inhibition of the relay cell by the interneuronal dendritic appendages (Paré et al., 1991).

Two major somatosensory afferent pathways, the medial lemniscus (ML) and the spinothalamic tract (STT), project to the ventroposterolateral nucleus (VPLc; Olszewski, 1952) of the thalamus in the primate (Boivie, 1978, 1979). The projections of the ML to VPLc arise from the dorsal column nuclei of the caudal brainstem. The major modalities conveyed by this system (e.g., touch, vibration, pressure) arise from rapidly and slowly adapting low-threshold (non-noxious) cutaneous mechanoreceptors, as well as some inputs from muscles and joints. A few cells in nucleus gracilis have been shown to receive convergent input from low-threshold and high-threshold (noxious) cutaneous mechanoreceptors (Ferrington et al., 1988).

Projections from spinal cord neurons carry noxious information, as well as non-noxious stimuli, from cutaneous and deep structures (Chung et al., 1986a) and terminate in VPLc as "parcellated bursts" (Mehler, 1962). STT axons exhibit a caudal to rostral arbor and occupy a subcomponent of VPLc where they are overlapped by the more abundant lemniscal afferents (Boivie, 1978, 1979; Ralston, 1984). Thus, it is anticipated that some of the neurons of VPLc would exhibit exclusively nonnoxious response properties, in that they would be driven only by ML afferents that project to the entire extent of the nucleus. Other VPLc neurons would be expected to exhibit convergent properties, being activated by both ML and STT afferents, or by the numerous dorsal horn STT neurons that receive convergent input from both noxious and non-noxious primary afferents (wide-dynamic-range neurons; Chung et al., 1986a). Physiological studies of macaque thalamic neurons (Chung et al., 1986b) found that more than half of the VPLc neurons responded exclusively or preferentially to noxious mechanical stimuli, the remainder responding in varying degrees to nonnoxious or to noxious stimuli.

Lemniscal and spinal projections to the thalamus are modulated in the dorsal horn and dorsal column nuclei, respectively, and then are subject to modulation in the thalamus. In this study, the synaptic relationships formed by lemniscal afferents with thalamocortical relay cells and GABA-ir interneurons were cxamined by clectron microscopy and compared to those of spinal afferents, following labeling of the afferents by WGAHRP. We demonstrate that the thalamic circuitry serving the pathways carrying non-noxious and noxious information, respectively, is fundamentally different, and we suggest some functional consequences that may result from these differences in circuitry.

\section{Materials and Methods}

This study is based upon the experimental material obtained from 11 young adult male $M$. fascicularis monkeys weighing from 7 to $10 \mathrm{~kg}$.
The animals were housed and cared for pre- and postoperatively according to the NIH and the USDA regulations along with the guidance of the Committee for Animal Research of UCSF and the veterinary care of the Animal Care Facility of the University of California at San Francisco. Following approved protocol, the animals were immobilized with ketamine hydrochloride $(10 \mathrm{mg} / \mathrm{kg}, \mathrm{i} . \mathrm{m}$.) and anesthetized with sodium pentobarbital (1:1 in isotonic saline, i.v.), titrated to an appropriate anesthetic level for surgery and the anesthesia maintained with a pentobarbital intravenous infusion of $5 \mathrm{mg} / \mathrm{kg} / \mathrm{hr}$.

ML projcctions were studied in four animals, each being placed in a Kopf stereotaxic head holder using an inverted mouthpiece to hold the head in a flexed position. Using sterile surgical techniques, a midline incision and reflection of muscle were performed at the level of the caudal occiput to expose the atlanto-occipital membrane, which was then incised in order to visualize the dorsal column nuclei. Five percent wheat germ agglutinin conjugated to horseradish peroxidase (WGAHRP) in sterile saline was pressure injected into the cuneate nucleus, using a Hamilton syringe onto which was attached a micropipette with a tip diameter of $40-50 \mu \mathrm{m}$. Injections were placed approximately 2 $\mathrm{mm}$ apart and each injection consisted of $0.02-0.04 \mu \mathrm{l}$ in volume, the total volume injected being approximately $0.1 \mu \mathrm{l}$. In the seven animals used for spinothalamic projections, the cervical $(n=4)$ or the lumbar $(n=3)$ enlargement of the spinal cord was surgically exposed after a laminectomy and 5\% WGA-HRP was pressurc injected into the dorsal horn of the cord, medial to the dorsal root entry zone. Injections were placed approximately $2 \mathrm{~mm}$ apart rostrocaudally and each injection was $0.02-0.04 \mu \mathrm{l}$ in volume, the total volume injected over the enlargement being approximately $0.14 \mu \mathrm{l}$, labeling about two or three consecutive spinal segments. The injections labeled extensive regions of the dorsal and ventral horn gray matter (see Fig. 1 in Ralston and Ralston, 1992).

The animals survived for 3-5 d to minimize transneuronal labeling of postsynaptic structures (Peschanski and Ralston, 1985), at which time they were reanesthetized and perfused intracardially with phosphatebuffered saline (PBS) followed by $2 \%$ paraformaldehyde, $2 \%$ glutaraldehyde. The brain and spinal cord were removed and the thalamus was blocked in the stereotaxic plane (Olszewski, 1952) and the injected segments of the medulla and cord cut into transverse blocks. The injection sites and the thalamus were serially sectioned with a Vibratome at $100 \mu \mathrm{m}$ thickness. Sections of brainstem, cord, and thalamus were incubated histochemically for the reaction for HRP for light microscopy (Mesulam, 1978) and separately for electron microscopy. For light microscopy, cord, medulla, and thalamus sections were mounted on slides in serial order to determine the extent of the injection and projection sites, respectively. Thalamic sections for electron microscopy were processed using ammonium molybdate and tetramethylbenzidine (TMB) overnight (Olucha et al., 1985). Adjacent sections of thalamus were stained for Nissl substance. After reaction with TMB, specific regions of somatosensory thalamus demonstrating anterograde axonal transport were identified and dissected out of the section and osmicated overnight (Henry et al., 1985). The tissue was prepared for electron microscopy using standard embedding and sectioning procedures. Thin sections were processed on the grid for the immunocytochemical detection of GABA (primary antibody: GABA, Incstar Corp.) with the secondary antibody conjugated to $10 \mathrm{~nm}$ colloidal gold (goat anti-rabbit IgG; Biocell Colloidal Gold Probes, T. Pella, Inc.) using a postembedding technique (deZeeuw et al., 1988) adapted and modified for our laboratory's experimental conditions (Ralston and Milroy, 1992). Control sections for our technique were incubated in a solution from which the primary antibody had been omitted, which resulted in the absence of the goldlabeled antibody over thalamic structures. The sections on the grid were then stained with uranyl acetate and lead. Semithin sections from the same block were used as a guide for the location of labeled profiles in the thin sections. The thin sections were viewed and photographed using a JEOL 100CXII electron microscope.

ML or STT axon terminals were identified by the presence of crystalline HRP reaction product. Although WGA-HRP is selectively transported by finer-diameter afferent axons in the PNS (Robertson and Grant, 1985), we believe that WGA-HRP labels all populations of lemniscal and spinal afferents. We have previously studied both systems identified by experimentally induced degeneration (Ralston, 1984; Ralston and Ralston, 1987) and the synaptic relationships formed by degenerating ML or STT terminals are identical to those described in the present study.

Profiles were considered GABA-ir when the density of gold particles per square micrometer within the confines of a structure exceeded five times the level of background, the latter measured over capillary en- 
dothelial cells or capillary lumens. The numbers of synaptic contacts made by ML or STT terminals and the type of postsynaptic structure were evaluated by tracking across the section (each track being $5 \mu \mathrm{m}$ wide at $10,000 \times$ magnification) and counting every identifiable structure on which a clearly defined synapse could be visualized in a single section. At the end of the track, the section was moved $10 \mu \mathrm{m}$ and the procedure repeated. We identified postsynaptic structures as (1) non GABA-ir dendrites of relay cells, (2) vesicle-containing GABA-ir presynaptic dendrites of interneurons, or (3) GABA-ir dendritic shafts of local circuit neurons. We also recorded the type of synaptic relationships: (1) simple axodendritic, (2) triads (ML or STT afferent, interneuronal presynaptic dendrite, relay neuron dendrite), (3) glomeruli (ML or STT afferent, multiple presynaptic dendrites, relay cell dendrite). We counted more than 300 labeled ML terminals in the forelimb area of VPLc in specimens from three animals and nearly 200 labeled STT terminals in the forelimb area of VPLc in two animals. Other regions of the somatosensory thalamus receiving spinal afferents (the posterior group, $\mathrm{Po} / \mathrm{SG}$; and the central lateral nucleus, $\mathrm{Cl}$ ) were also examined.

$\mathrm{ML}$ and STT terminals in series of thin sections ranging in number from 25 to 75 were reconstructed by computer in order to evaluate the three-dimensional synaptic relationships with relay neuron and interneuron dendrites, as well as the presence or absence of other synaptic types that made contact with the segment of relay cell dendrite being studied. The profiles in serial electron micrographs were digitized and entered into an IBM-based three-dimensional reconstruction program from the Laboratory of High Voltage Electron Microscopy at the University of Colorado, Boulder. Completed reconstructions were photographed directly from the computer screen.

\section{Results}

\section{Light microscopy}

We examined the WGA-HRP transport to VPLc following microinjections of the tracer into the contralateral cuneate nucleus, or cervical or lumbar enlargements. Cuneatus projections were characterized by heavy label throughout the rostrocaudal extent of VPLc. Spinal injections resulted in discrete clusters of terminal axonal arbors in the somatotopically appropriate region of the VPLc nucleus of the thalamus, upper extremity representation being medial to that of the lower extremity. A given cluster of labeled STT axons is about $500 \mu \mathrm{m}$ wide and extends caudally to rostrally for $1-2 \mathrm{~mm}$.

\section{Electron microscopy}

$M L$ terminals. Samples of VPLc taken from regions exhibiting labeled ML axons reveal numerous examples of crystalline HRP reaction product in their terminals. The labeled ML terminals are of the RL profile type (see introductory remarks), in that they have numerous rounded synaptic vesicles and are large (2$3 \mu \mathrm{m}$ in greatest diameter measured in a single section) and contain several mitochondria. The labeled ML terminals synapse upon two types of profiles: those that contain pleomorphic synaptic vesicles, and those that do not (Fig. 1). In sections processed for GABA-ir, the postsynaptic profiles that contain synaptic vesicles are invariably GABA-ir (Figs. 2, 3,6) and we interpret them to be the vesicle-containing dendritic appendages (presynaptic dendrites) of interneurons. In addition to being postsynaptic to ML afferents, presynaptic dendrites synapse upon small-diameter ( $<1 \mu \mathrm{m}$ ), non-GABA-ir dendrites (Fig. 4), presumed to be the more distal dendrites of relay neurons, or upon other presynaptic dendrites (not shown).

The profile type without synaptic vesicles that is postsynaptic to ML terminals tends to be larger than the vesicle-containing presynaptic dendrites ( $>1 \mu \mathrm{m}$ in diameter compared to $<1 \mu \mathrm{m}$, respectively) and never exhibits GABA-ir. We assume that these profiles are the dendritic shafts of relay neurons. The apposing pre- and postsynaptic membranes of the ML terminals and the relay neuron dendrites often exhibit two types of specialization

\begin{tabular}{lcc}
\hline Table 1. ML contacts with ventrobasal neurons & \\
& $n$ & \% of total \\
\hline $\begin{array}{l}\text { ML synapses } \\
\text { With relay cell dendrites }\end{array}$ & 231 & 54 \\
$\begin{array}{l}\text { With presynaptic } \\
\text { dendrites (GABAergic) }\end{array}$ & 180 & 42 \\
With interneuronal & & \\
$\quad \begin{array}{l}\text { dendritic shafts } \\
\text { (GABAergic) }\end{array}$ & 17 & 4 \\
ML terminals & Forming triads & \\
$\quad$ Forming glomeruli & 102 & 30 \\
\hline
\end{tabular}

$n=339$ labeled terminals forming a total of 428 synaptic contacts.

(Fig. 1). The first shows an accumulation of vesicles against the presynaptic membrane and an increased density of the postsynaptic leaflet; the other shows localized increased densities of both pre- and postsynaptic membranes, without vesicle accumulation.

We also identified two other GABA-ir profile types in VPLc: myelinated axons and terminals $(F)$ that we assume arise from these axons. The GABA-ir terminals differ morphologically from the GABA-ir presynaptic dendrites: they contain more numerous, larger mitochondria and more synaptic vesicles than do presynaptic dendrites (Figs. 2, 7). On occasion these F profiles synapse upon presynaptic dendrites (Fig. 7b). The GABA-ir axon terminals are never postsynaptic to ML axons or to any other presynaptic profile, in contrast to the relationships of the GABA-ir dendrites.

The synaptic relationships formed by ML afferents were classified (see Materials and Methods) as simple, triadic, and glomerular. Most triadic and all of the glomerular synaptic arrangements require serial section analysis to demonstrate the complex synaptic relationships (e.g., Fig. 8; Ralston, 1991). Following the classification of synaptic type, counts were made of synaptic contacts formed by more than $300 \mathrm{ML}$ terminals in VPLc in thin sections from three animals and are shown in Table 1 . The results were approximately the same in each animal, so we chose to pool the counts. In summary, when viewed in single sections, about $54 \%$ of the synaptic contacts formed by ML terminals are with relay neuron dendrites and about $46 \%$ are with the vesicle-containing dendritic appendages or the GABA-ir dendritic shafts of interneurons. In serial sections, ML terminals can be seen to form complex synaptic relationships (triads and glomeruli) in more than $80 \%$ of cases.

Three-dimensional, computer-assisted reconstructions of the synaptic relationships formed by ML terminals were carried out on five different ML terminals from two animals. Examples of one of the reconstructions are shown in Figure 8 . The reconstructions reveal several aspects of the synaptic relationships that are not apparent in single micrographs.

(1) The ML afferent that contacts a given segment of relay neuron dendrite is always found to arise from a single axonal profile that may extend for several micrometers along the postsynaptic dendrite. The ML afferent forms multiple active zones of synaptic contact with the relay neuron dendritic segment.

(2) Serial section reconstructions demonstrate that, when a single section shows an ML profile to synapse upon a relay neuron dendrite and upon one or more GABA-ir dendrites, all of the GABA-ir dendrites synapse upon the relay cell dendrite. 

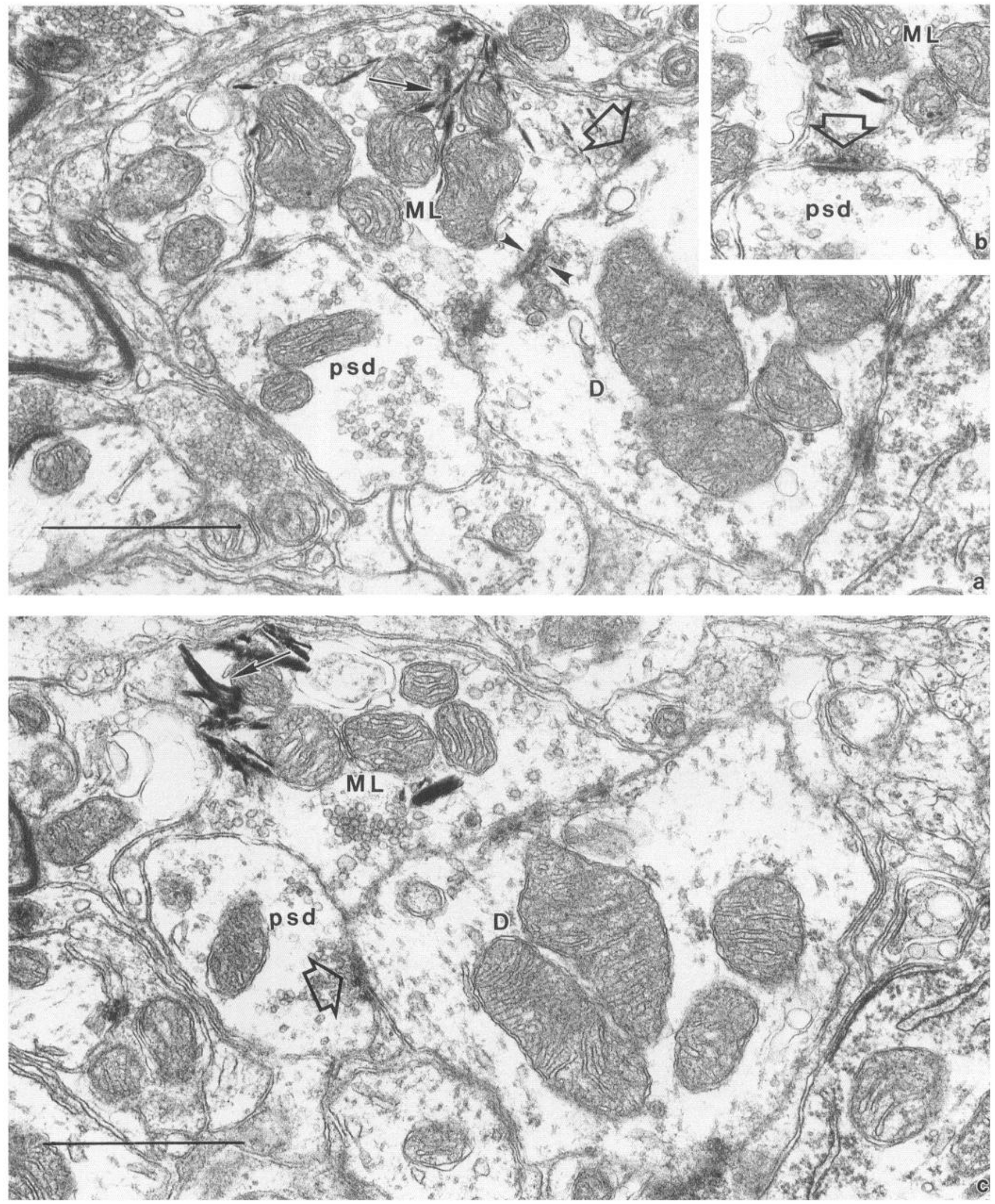

Figure 1. $a-c$, Photomicrographs of serial sections in VPLc, each being three sections distant from the previous one. A labeled ML terminal exhibits HRP reaction product (arrows) and is engaged in a triadic synaptic arrangement with a relay cell dendrite $(D)$ upon which it synapses (open arrow in $a$ ). $M L$ also synapses upon a presynaptic dendrite $(p s d)$ of an interneuron (open arrow in $b$, inset) and the postsynaptic dendrite, in turn, synapses upon $D$ in $c$. An example of a filamentous contact between $M L$ and $D$ is indicated by the small dark arrowheads in $a$. Scale bars, $1 \mu \mathrm{m}$. 


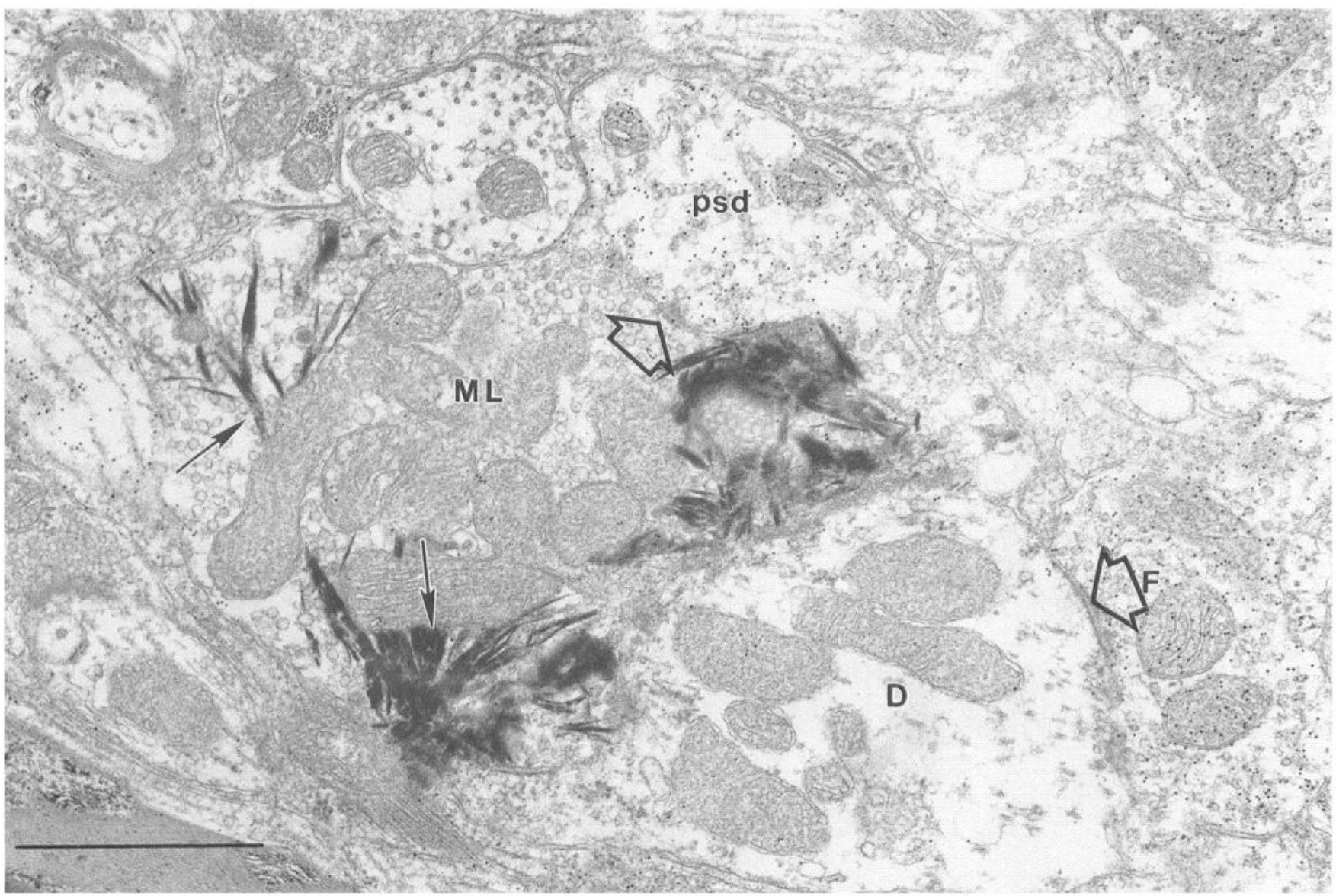

Figure 2. A labeled ML synaptic terminal contacts a relay cell dendrite $(D)$ (in an adjacent section), which is not GABA-ir, and a presynaptic dendrite (psd) (open arrow) that exhibits the $10 \mathrm{~nm}$ gold particles used to identify the GABA antibody. The profile $F$ is also GABA-ir, and synapses (open arrow) upon $D$. $F$ is interpreted as a GABA-ir axon terminal. Scale bar, $1 \mu \mathrm{m}$.

(3) There are one or more GABA-ir axon terminals (F; see Fig. 2) that synapse upon the segment of relay cell dendrite receiving the ML input.

(4) For the segment of relay cell dendrite receiving an ML input, there are no other RL terminals that synapse upon the relay neuron dendrite.

STT terminals. Labeled spinal afferents to VPLc have an RL morphology similar to that of ML terminals in that they contain rounded synaptic vesicles, are large profiles, $2-3 \mu \mathrm{m}$ in greatest diameter (measured in a single section), and make asymmetrical contacts with dendrites of VPLc neurons. STT terminals form predominantly axodendritic contacts upon larger-diameter dendrites ( $>1 \mu \mathrm{m}$ in diameter) that are not GABA-ir and are interpreted as being the dendritic shafts of relay neurons. STT terminals occasionally synapse upon spines of relay neuron dendrites (Fig. 10). Often, multiple STT terminals synapse along the entire length of a given dendritic segment seen in a single semithin (Fig. 9) or in thin sections (Figs. 11-13). When followed in serial sections, these individual labeled STT terminals do not arise from a single stem axon.

In about $15 \%$ of cases, STT terminals contact GABA-ir dendritic appendages of interneurons but, when followed in serial sections, the appendage may or may not synapse upon the relay neuron dendrite that is postsynaptic to the STT. Only occasionally, an STT terminal synapses simultaneously upon a relay cell dendrite and a presynaptic dendrite, the latter synapsing upon the relay neuron to form a triadic relationship. Counts of the synaptic relationships formed by STT axons are given in Table 2.

We also examined the synaptic relationships of STT terminals in $\mathrm{Po} / \mathrm{SG}$ and in $\mathrm{Cl}$ nucleus of the intralaminar thalamus. They appear to be qualitatively similar to those described above for VPLc, in that the STT afferents primarily end as simple axodendritic synapses upon non-GABA-ir dendrites.

Three-dimensional computer-assisted reconstructions (Fig. 14) of the synaptic relationships formed by labeled STT terminals were carried out on four samples from three animals. The reconstructions revealed the following.

(1) Several individual STT terminals contact a given segment

Table 2. STT contacts with ventrobasal neurons

\begin{tabular}{lll} 
& $\begin{array}{l}\text { Synaptic } \\
\text { contacts }\end{array}$ & $\begin{array}{l}\% \text { of } \\
\text { total }\end{array}$ \\
\hline $\begin{array}{l}\text { STT synapses with relay cell dendrites } \\
\text { STT synapses with presynaptic den- } \\
\text { drites (GABAergic) }\end{array}$ & 162 & $85 \%$ \\
$\begin{array}{l}\text { STT terminals forming triads or glo- } \\
\text { meruli }\end{array}$ & 28 & $15 \%$ \\
$n=190$ STT terminals. & 4 & $2 \%$ \\
\hline $\begin{array}{l}n \\
\text { m }\end{array}$ & &
\end{tabular}




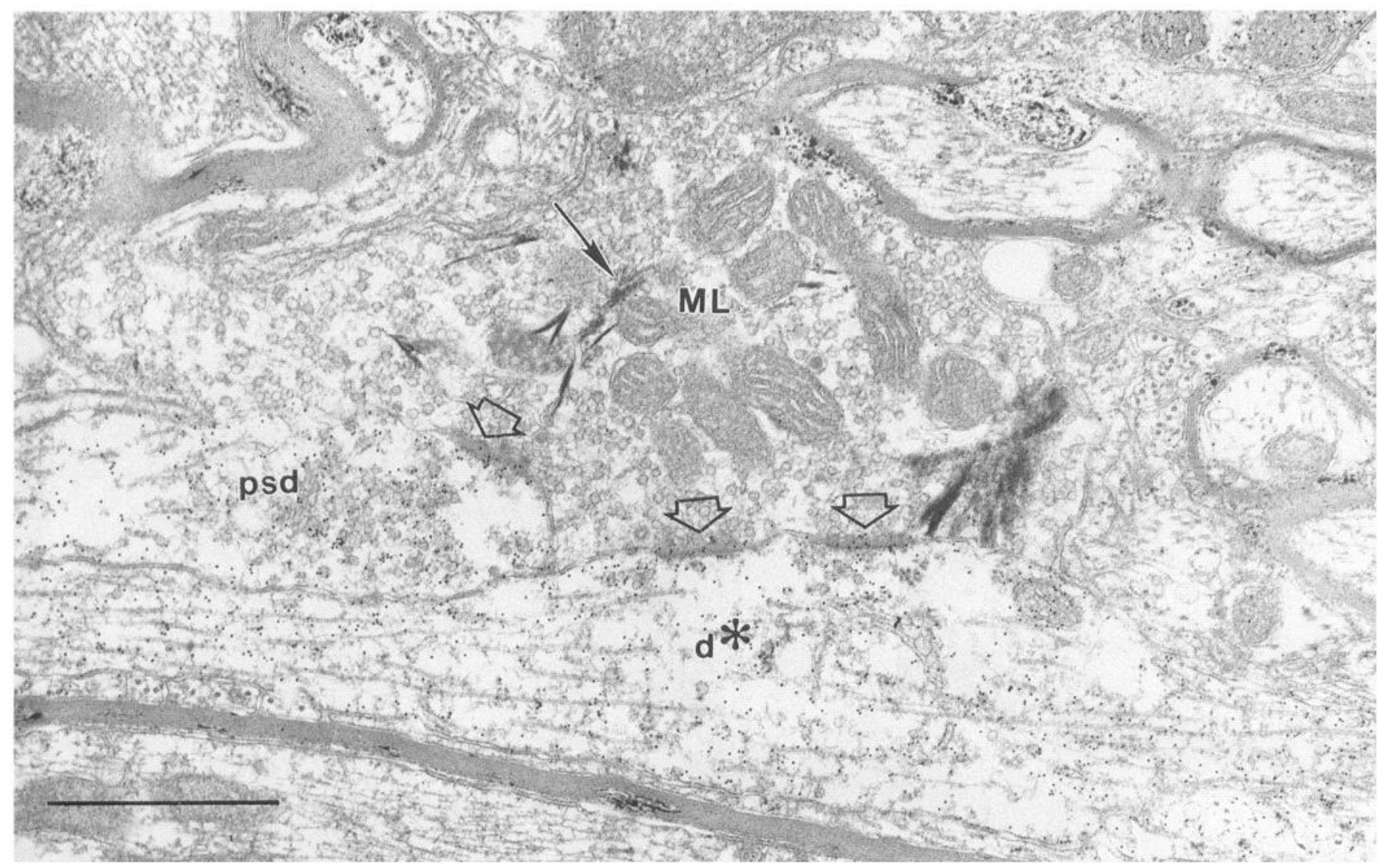

Figure 3. A labeled ML terminal synapses upon the shaft of a GABA-ir interneuronal dendrite $\left(d^{*}\right)$ at the open arrows, as well as upon a vesiclecontaining presynaptic dendrite $(p s d)$. Note that the gold labeling of the GABA antibody is present along microtubules and other regions of the interneuronal dendrite, as well as in the zones containing synaptic vesicles in the presynaptic dendrite. Scale bar, $1 \mu \mathrm{m}$.

of relay cell dendrite and these afferents form multiple synaptic contacts (active zones) with the relay cell dendrites.

(2) STT afferents only occasionally contact GABA-ir dendritic elements; only two such contacts were observed out of more than two dozen STT profiles reconstructed.

(3) The segment of relay cell dendrite that receives STT synapses is infrequently contacted by either a GABA-ir dendritic appendage or by GABA-ir axonal profiles.

(4) For the segment of relay cell dendrite receiving an STT input, there are no other RL terminals that synapse upon the relay neuron dendrite.

\section{Discussion}

The major finding of this study (shown diagrammatically in Fig. 15 ) is that the synaptic interactions of STT afferents with GABAir interneurons is substantially different than those of the ML in that most STT terminals form simple axodendritic synapses with relay cell dendrites but have few synaptic relationships with GABA-ir presynaptic dendrites. In contrast, the substantial majority of lemniscal terminals form synaptic triadic and glomerular arrangements with GABA-ir presynaptic dendrites and the dendritic shafts of thalamocortical relay neurons. Thus, there is little potential for immediate disynaptic GABAergic modulation of the STT activation of relay cells, but such modulation would be expected to be a prominent feature of ML interactions with relay neurons. Most STT axons convey information arising from noxious stimuli, and we suggest that it is this population of STT afferents that do not have their excitatory inputs mod- ulated by GABA-containing interneurons. However, the synaptic effects of ML afferents, almost all of which carry nonnoxious information, are substantially modulated by GABAergic presynaptic dendrites.

About $15 \%$ of STT terminals do make synaptic contacts with GABA-ir presynaptic dendrites. This group of STT terminals may transmit the non-noxious information carried by a subcomponent of the STT in primates (Willis and Coggeshall, 1991). On the other hand, the ML carries information from rapidly adapting and slowly adapting mechanoreceptors, located in cutaneous and deep structures (reviewed in Willis and Coggeshall, 1991). Whether the differing synaptic relationships in triads or glomeruli formed by ML terminals is related to the different sensory modalities conveyed by the ML afferents is not known.

Differences in the synaptic relationships of sensory afferents with interneurons have also been described in the visual thalamus. Retinal $\mathrm{X}$ and $\mathrm{Y}$ ganglion cells that project to cat LGN are physiologically different, in that they possess different conduction velocities, vary in their responses to visual stimuli, and have different receptive field sizes. $\mathrm{X}$ and $\mathrm{Y}$ cell axonal synaptic relationships with $L G N$ neurons are different in that $\mathrm{X}$ retinal afferents have a greater interaction with interneurons than do Y afferents (Wilson et al., 1984). Rapisardi and Miles (1984) found that retinal afferents synapsing upon the $\mathrm{X}$ category of cat LGN relay neurons form numerous triadic synaptic arrangements with presynaptic dendrites and the dendrites of these relay neurons. In contrast, retinal afferents that synapse upon the dendrites of the $\mathrm{Y}$ category of LGN neurons make primarily 


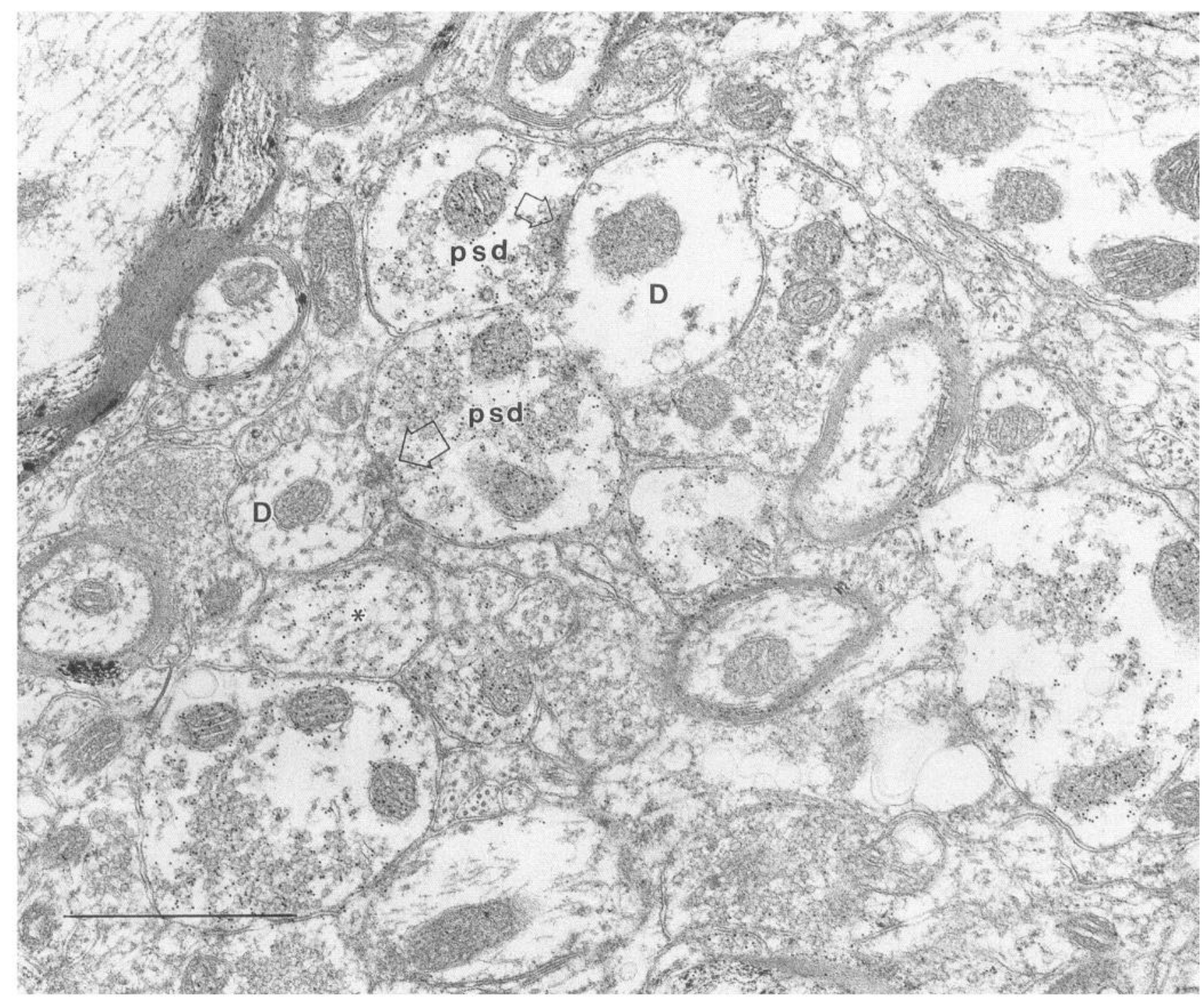

Figure 4. Several GABA-ir presynaptic dendrites ( $p s d)$, interpreted as cross sections through the dendritic appendages of interneurons, synapse upon non-GABA-ir dendrites $(D)$ interpreted as fine diameter branches of relay cells. The profile $\left({ }^{*}\right)$ contains GABA-gold labeling but lacks synaptic vesicles. It is probably a dendritic shaft of an interneuron such as that seen in longitudinal section in Figure 3 . Note the differences in immunogold labeling between the GABA-ir and non-GABA-ir profiles. Scale bar, $1 \mu \mathrm{m}$.

simple axodendritic synapses upon their dendrites, with little involvement with interneurons. Wilson (1989) has described a similar difference in synaptic relationships formed by retinal afferents in the macaque LGN, where he found that retinal afferents to magnocellular neurons commonly formed triadic relationships with relay neurons and interneurons, but the retinal afferents to the parvocellular layers tended to make simple axodendritic synapses, rarely involving triads. Therefore, differential GABAergic processing of sensory signals may be a general mechanism used by the thalamus to modulate selectively the information carried by these afferents.

\section{Neuronal cell types in VPLC}

The macaque monkey is similar to the cat in that the major thalamic nuclei contain two principal classes of neurons: thalamocortical relay cells, which project to the appropriate cortical target, and interneurons (local circuit), the processes of which are confined to the nucleus of origin (reviewed in Jones, 1985).
Relay cells are not GABA-ir and may be identified by light and electron microscopy by their characteristic morphology (Ohara and Havton, 1993) and by their labeling with HRP following retrograde axonal transport of the tracer from the somatosensory cortex (Spreafico et al., 1983). Relay neurons that receive synapses from ML (Fig. 1) and STT (Fig. 12) afferents exhibit two forms of postsynaptic membrane specialization, active zones and filamentous contacts, originally described in the LGN (Colonnier and Guillery, 1964). Active zones reveal an accumulation of vesicles against the presynaptic membrane and are assumed to be the site of neurotransmitter release. Filamentous contacts lack this accumulation of synaptic vesicles and may serve an adhesive function between pre- and postsynaptic elements.

Interneurons are GABA-ir and possess dendritic shafts and appendages that contain synaptic vesicles (Ralston and Herman, 1969; Ralston, 1971; Famiglietti and Peters, 1972; Spreafico et al., 1983; Ohara et al., 1989). The subsynaptic densities of in- 


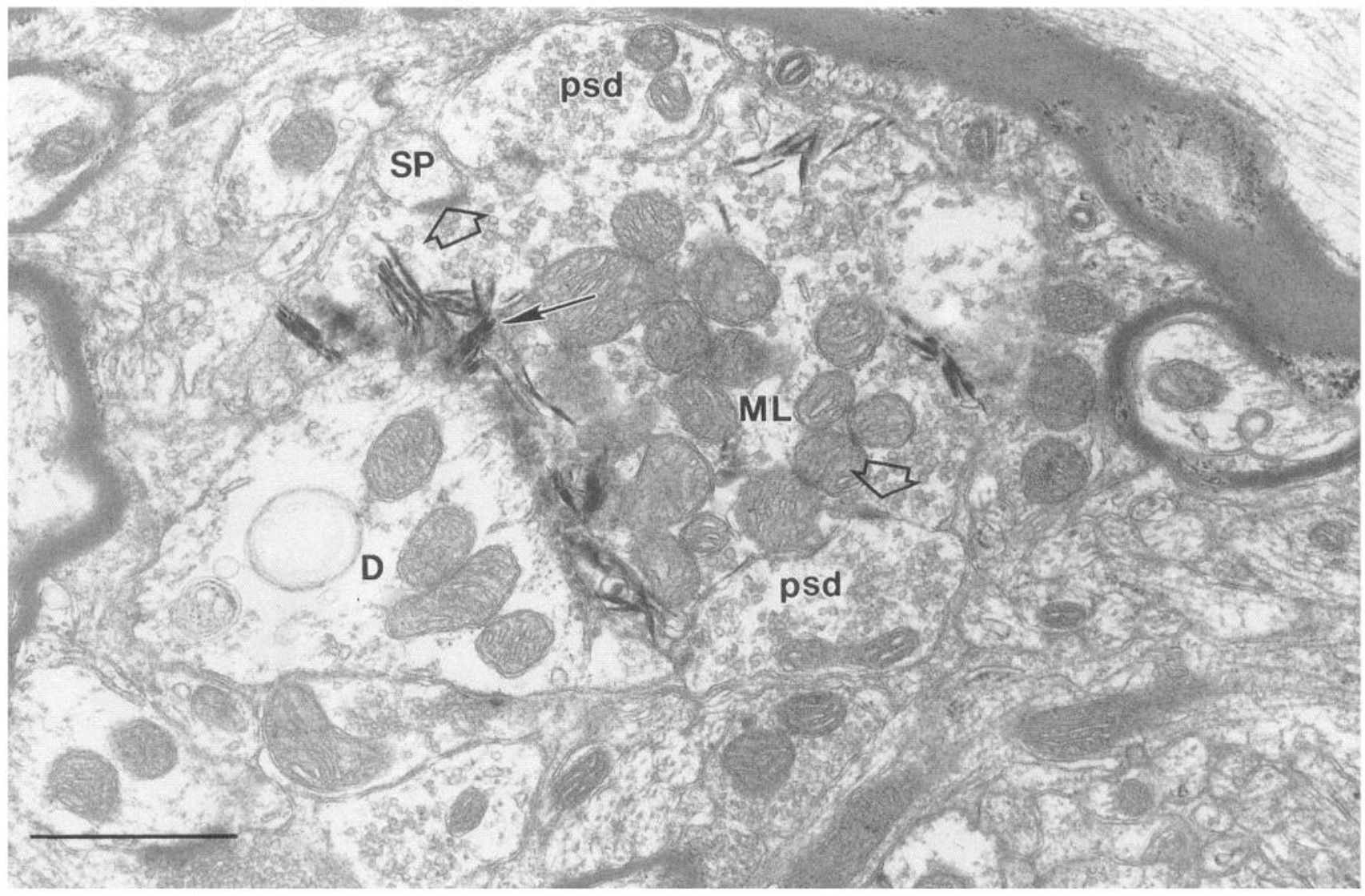

Figure 5. A glomerular synaptic complex formed by a labeled ML profile that synapses (open arrows) upon a dendritic spine (SP) without synaptic vesicles, and dendritic appendages that contain synaptic vesicles. When such glomerular complexes are reconstructed from serial sections, the latter profiles all form synapses upon the dendritic shaft of the relay cell $(D)$ and are thus interpreted as presynaptic dendrites $(p s d)$. Scale bar, $1 \mu$ m.

terneurons that are postsynaptic to ML (and the occasional STT) afferents are usually one in number (Figs. 1-3,6), and are always associated with an accumulation of vesicles near the presynaptic membrane of the ML terminal. The nonsynaptic filamentous contacts formed by ML terminals on relay cell dendrites are not found between ML terminals and GABA-ir dendrites. This difference in synaptic specialization between afferents and relay cells or afferents and interneurons further identifies the postsynaptic elements in VPLc. In addition, GABA-ir is present in interneuronal dendrites, whether or not vesicles are present (see Figs. 3, 4, 11), thus simplifying their identification in electron micrographs. Although it is possible that some LCN dendrites contain so little GABA as not to be revealed by our immunocytochemical technique, we believe that this is unlikely. All profiles that contain pleomorphic vesicles, which numerous earlier studies have presumed to arise from GABAergic dendrites or axons, exhibit substantial GABA antibody labeling in our study. Therefore, we believe that our identification of the den- drites of the GABA-ir interneurons and the non-GABA-ir relay cells is correct. This conclusion is further substantiated by a study (Ohara et al., 1989) in which we intracellularly labeled relay neurons and interneurons in VPLc. We compared the light microscopic dendritic morphologies of the two classes of cells with their appearance revealed by electron microscopy and found that the relay cell dendritic profiles and the interneuronal dendritic appendages have the same distinct features as those described in the present study.

\section{The role of interneurons in thalamic mechanisms}

GABA-containing interneurons are believed to be able to release their neurotransmitter both from their dendritic appendages and from their axon (Ralston, 1971). Whether all thalamic interneurons have axons is debatable. Interneurons exhibiting axons have been reported (Guillery, 1966; Tömböl, 1969) in Golgistained cat LGN, and Hamos et al. (1985) described them in a study of intracellularly labeled neurons in the same nucleus.

Figure 6. A labeled ML terminal synapses (open arrow) upon one GABA-ir presynaptic dendrite (psd) and is adjacent to two others. Serial reconstruction revealed that ML contacted all presynaptic dendrites and that a relay cell dendrite lay deep to these structures and was synapsed upon by the ML and the presynaptic dendritic profiles. Scale bar, $1 \mu \mathrm{m}$.

Figure 7. Examples of GABA-ir F profiles. In $a, F$ synapses (open arrow) upon a relay cell dendrite $(D)$. In $b, F$ synapses (open arrow) upon a presynaptic dendrite $(p s d)$. Note the differences in mitochondria and synaptic vesicle distribution in these two GABA-ir profiles. $F$ terminals are interpreted as arising from GABA-ir axons. Scale bars, $1 \mu \mathrm{m}$. 

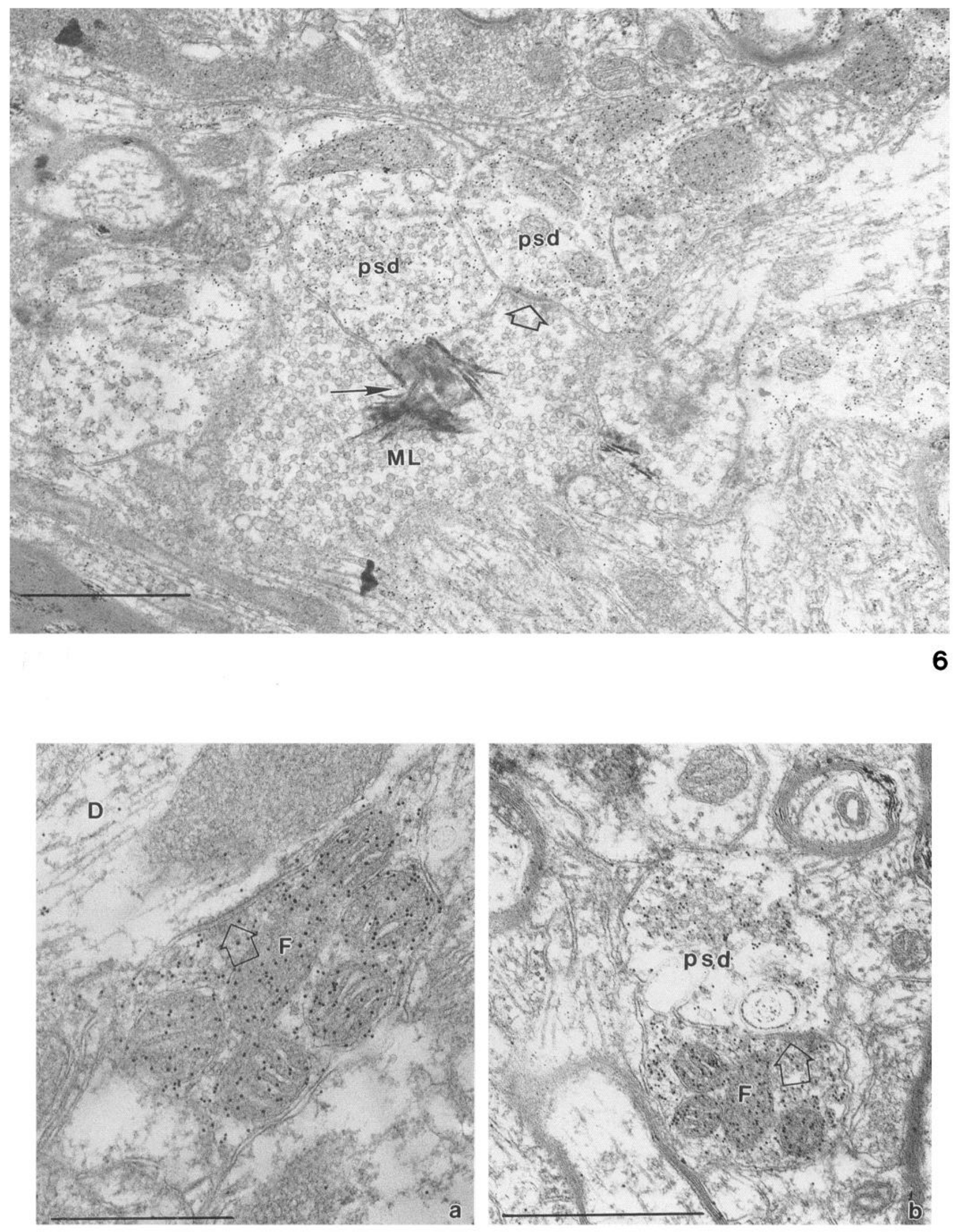

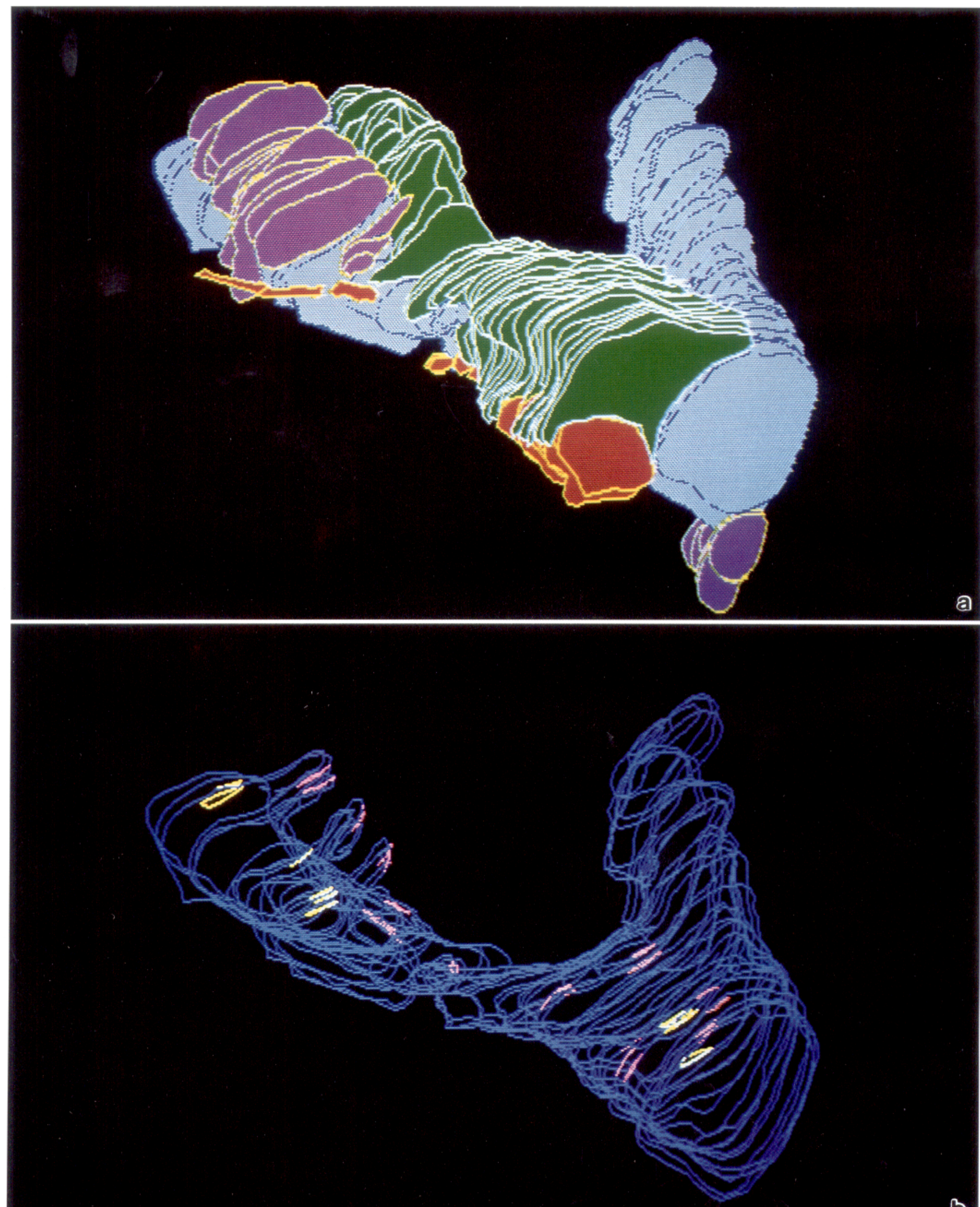

Figure 8. Computer-assisted three-dimensional reconstructions of the synaptic relationships formed by an ML terminal (green), a relay cell dendrite (gray), and a GABA-ir presynaptic dendrite of an interneuron (red). $a$, The ML lies along the branch point of the relay cell dendrite. A nearby $\mathrm{F}$ 
However, other studies of intracellularly labeled interneurons have failed to demonstrate axons arising from their cell bodies (Yen et al., 1985), even when examined in serial thin sections. Interneurons have been shown to respond to peripheral stimuli with trains of action potentials (Wilson, 1989; P. T. Ohara, personal communication), presumably as a result of synaptic contacts made by afferents onto dendritic shafts of the cell (see Fig. 3). It is possible that such cells have spike-generating zones at the origin of axons arising from their dendrites.

The most thorough study of the functional properties of the GABAergic presynaptic dendritic appendages of interneurons in processing afferent information in the thalamus is that of Pare et al. (1991). These authors examined the interactions of mammillary body afferent axons with relay cells and presynaptic dendrites in the cat anterior nuclear complex. They chose this nucleus as a model because it receives few GABAergic axons from the thalamic reticular nucleus (TRN), which might otherwise obscure the effects of GABA released by interneurons. They described a triphasic series of IPSPs in relay cells following stimulation of mammillothalamic afferents: a short-latency, briefduration IPSP (designated a) that they concluded was due to feedforward inhibition mediated by the triadic synaptic relationships between mammillary afferents, interneuronal presynaptic dendrites, and relay cells; and two longer-latency, more prolonged IPSPs (designated A and B) that they assumed were evoked by the axons of interneurons. They showed that a and A were mediated by $\mathrm{GABA}_{\mathrm{A}}$ receptors, and that the B IPSP was due to activation of $\mathrm{GABA}_{\mathrm{B}}$ receptors. Given the small size of the interneuron and its dendritic appendages and the consequent high input resistance, they concluded that afferent stimulation was probably very effective in evoking release of GABA from the presynaptic dendrites. They suggested that the short-duration IPSPs in relay cells resulting from afferent activation of presynaptic dendrites would promote effective information transfer by the relay cells by reducing postsynaptic summation, leading to the rapid return of the relay cell to its resting potential to permit higher frequency of information transfer. Assuming that the findings of Paré et al. are applicable to the primate somatosensory thalamus, it is likely that the information transfer between STT afferents and relay cells, relatively unmodulated by GABAergic presynaptic dendrites, is substantially different than that evoked by stimulation of the ML.

We have found that more than $80 \%$ of the ML afferents to macaque VPLc are involved in complex synaptic relationships with relay cells and interneurons. In addition, the three-dimensional reconstructions reveal that GABA-ir axon terminals (F) contact the same segment of relay cell dendrite that is involved in the triadic or glomerular synapses with the ML afferents. F profiles could be the terminals of axons (if present) of interneurons, or could arise from the GABAergic cells of the TRN (Ohara et al., 1983; Peschanski et al., 1983). Whatever the origin of the $\mathrm{F}$ terminals, it is believed that they produce the longer-duration

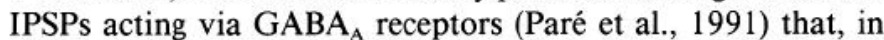
turn, may lead to de-inactivation of a low-threshold calcium current with the subsequent generation of oscillatory burst rhythms that characterize slow wave sleep (reviewed in McCormick, 1992). F terminals synapsing on dendritic segments

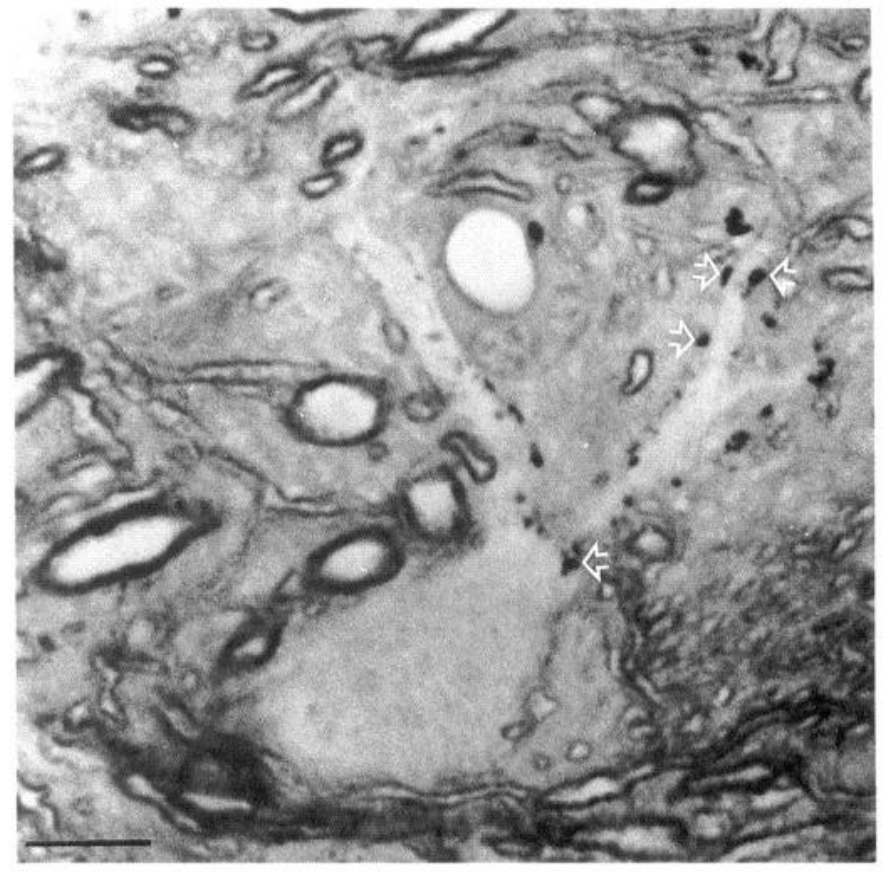

Figure 9. A semithin section ( $2 \mu \mathrm{m}$ in thickness) of a neuron in VPLc that receives STT input. Arrows point to HRP reaction product studding the dendrite. Electron microscopy revealed each of the structures at the arrows to be a labeled STT terminal. Scale bar, $10 \mu \mathrm{m}$.

near the afferent ML input may influence the transfer ratio of afferent signals to the cortex (reviewed by Wilson, 1989). In contrast, the segments of relay cell dendrites that receive STT input appear to have few GABA-ir axon terminals synapsing upon them, again indicating that the electrophysiological properties of these dendritic segments would be different from those receiving lemniscal input.

\section{Is there convergence of $M L$ and STT projections onto single thalamic neurons?}

Given the overlap of the terminal arbors of ML and STT axons in VPLc (Boivie, 1978, 1979), it is possible that some VPLc relay neurons receive convergent input from these two afferent systems, conveying fundamentally different sensory modalities. This creates a potential problem for the cerebral cortical neurons that are the recipients of information from such thalamocortical relay cells. However, the differences between the two afferent systems in synaptic interactions with GABAergic interneurons may result in distinct firing properties of relay neurons receiving ML and STT input, depending upon the degree of GABA modulation of the afferent signal, so that the cortex could distinguish between non-noxious and noxious information carried by convergent afferents upon thalamocortical cells. On the other hand, Rausell et al. (1992a) have suggested that macaque VPL neurons receiving either ML or STT input are spatially separated and characterized by the presence of different calcium-binding proteins (parvalbumin or calbindin D28k, respectively). Their conclusions suggest that there is little or no convergent input of the ML and STT afferents onto single VPLc cells and therefore the

terminal that contacts the relay cell dendrite is shown in purple. $b$, The synaptic terminals in $a$ have been removed to reveal the active synaptic zones formed by the ML (pink), by the presynaptic dendrite (yellow on dendritic stem) and by F (yellow on second-order branch). 


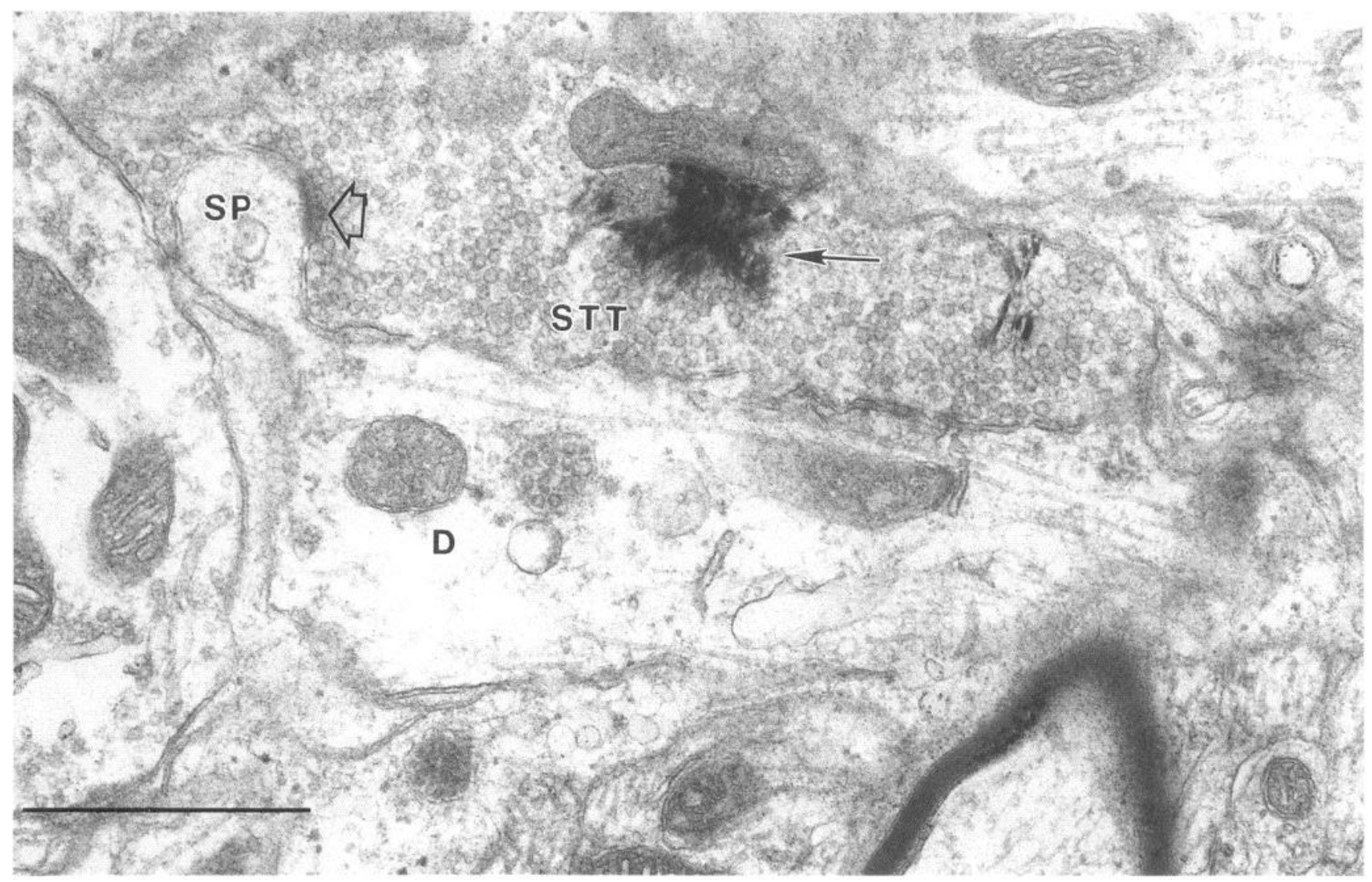

Figure 10. A labeled STT profile synapses upon the spine $(S P)$ of a relay cell dendrite $(D)$. The solid arrow points to HRP reaction product, and an open arrow indicates the synaptic contact. Scale bar, $1 \mu \mathrm{m}$.

information relayed to the cortex is transmitted by separate populations of thalamocortical neurons.

Three-dimensional reconstructions of ML or STT afferents reveal that a given segment of the relay cell dendritic arbor receives labeled terminals from one or the other source; for instance, RL profiles contacting a particular dendritic segment are labeled after dorsal column nuclei injection or after spinal cord injection, respectively. This is in contrast to thalamic convergence studies in the rat, in which degenerating lemniscal and HRP-labeled spinal terminals are found to be adjacent to one another, synapsing upon the same segment of dendrite in VPL (Ma et al., 1987). The rat VPL is fundamentally different than that of the monkey in another respect, in that GABA-ir interneurons are essentially absent in this nucleus in the rat (reviewed in Ralston, 1983).

The question of convergence of ML and STT afferents to single thalamic neurons awaits study of the synaptic terminations of these systems upon individual, intracellularly filled VPLc neurons, in which separate branches of the dendritic arbor can be examined to determine whether both ML and STT axon terminals contact the same neuron. This study is presently underway in our laboratory.

\section{Thalamic circuitry and pain mechanisms}

Our findings raise a hypothesis concerning the genesis of the thalamic pain syndrome (Dejerine and Roussy, 1906), also known as central post-stroke pain, which is characterized by severe pain and abnormalities in somatic sensibility. The CNS lesion, usually vascular in origin, is not necessarily located in the thalamus but may involve diverse regions of the diencephalon or brainstem and appears to be associated with central somatosensory deafferentation, particularly of the spino-thalamo-cortical pathways (Boivie et al., 1989). One possible explanation for these painful syndromes following central lesions may be the reorganization of thalamic circuitry in response to afferent injury. It has been observed that, after lesions of lemniscal afferents to the thalamus, there is a reduction of GABA-ir presynaptic dendrites within VPLc (J. Wells, personal communication), without apparent changes in the numbers of interneurons themselves. In another study, chronic deafferentation of the cord following extensive dorsal rhizotomy has been shown to result in transneuronal degeneration of the dorsal column nuclei, leading to decreases in $\mathrm{GABA}_{\mathrm{A}}$ receptors in VPLc (Rausell et al., $1992 b)$ without a reduction of GABA-ir interneurons. These examples indicate that $\mathrm{CNS}$ degeneration can lead to changes in thalamic GABAergic presynaptic dendritic appendages and postsynaptic $\mathrm{GABA}_{\mathrm{A}}$ receptors. Paré et al. (discussed above) have shown that the presynaptic dendritic appendages, acting via postsynaptic $\mathrm{GABA}_{\mathrm{A}}$ receptors, play a major role in setting the firing properties of thalamic neurons. In addition, Roberts et al. (1992) have demonstrated that alterations in inhibitory interactions mediated by $\mathrm{GABA}_{\mathrm{A}}$ receptors may participate in pathological pain states following CNS injury. In our study we have shown that ML inputs conveying non-noxious information have substantial interactions with GABA-ir interneurons; STT afferents, most of which carry noxious information, have sig- 


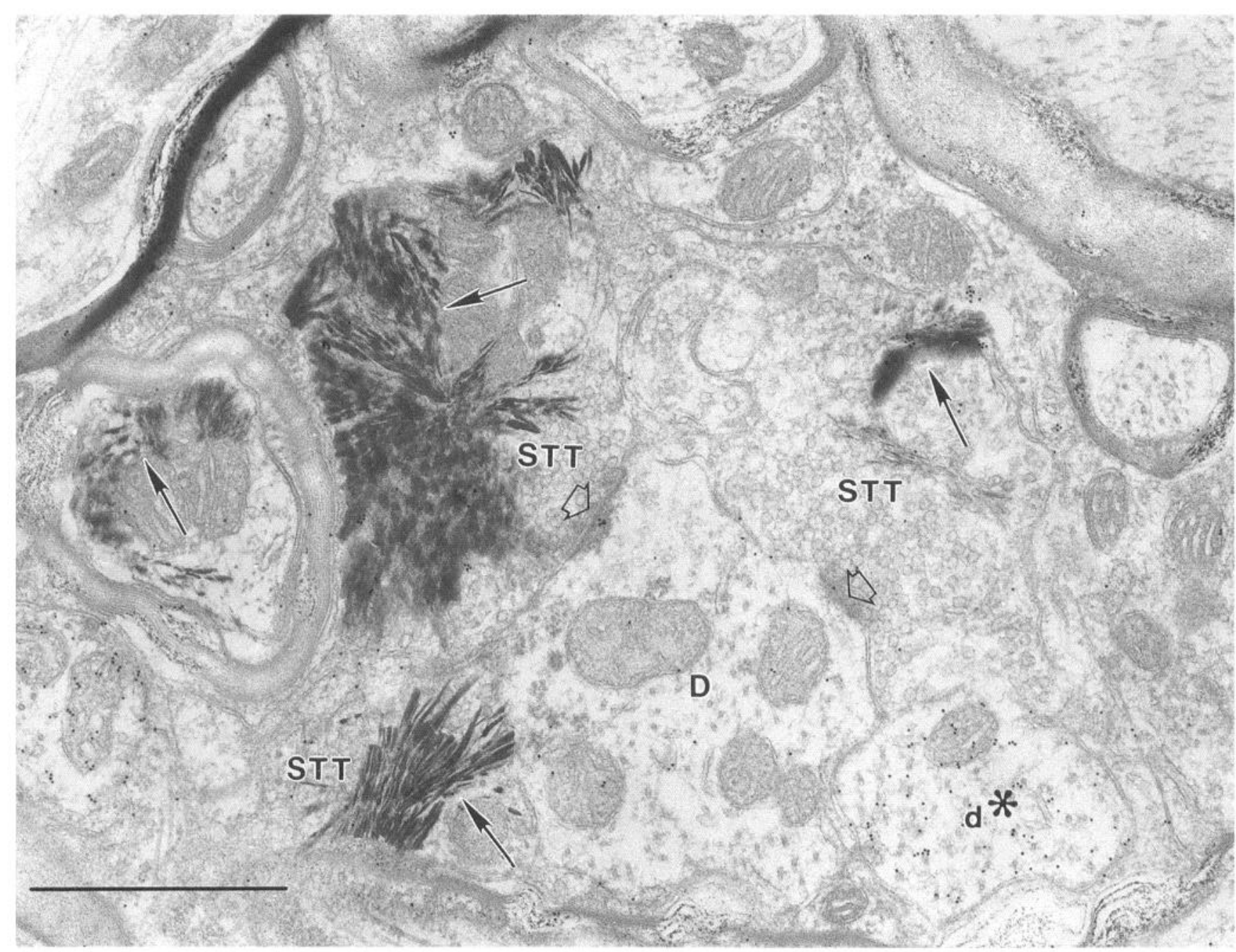

Figure 11. One of a series of electron micrographs from VPLc in which the tissue was immunoreacted for the presence of GABA and reconstructed in three dimensions. Labeled STT afferents from spinal cord synapse (open arrows) upon a relay cell dendrite (D). A GABA-ir dendritic profile lacking synaptic vesicles $\left(d^{*}\right)$ contains $10 \mathrm{~nm}$ gold particles, and did not receive a synaptic contact from an STT terminal. A nearby STT myelinated axon exhibits HRP reaction product (solid arrow). Scale bar, $1 \mu \mathrm{m}$.

nificantly less interactions with GABA-ir interneurons. The nature of the signals from relay neurons to cortex would be different, depending upon whether the input was GABA modulated or not. Our findings suggest that, in the primate thalamic transmission system, changes in the normal GABAergic circuitry following injury may cause the cortex to misinterpret non-noxious signals that are normally GABA modified in the thalamus to arise from nonmodified noxious stimuli, potentially resulting in central pain states.

\section{Conclusions}

Individual dendritic segments of thalamocortical relay neurons receive projections from either ML or STT afferent axons. Ap- proximately $84 \%$ of ML projections mediating non-noxious information to VPLc of the thalamus are involved in complex circuitry with GABA-ir interneurons, presumably modulating the effects of the ML input upon relay neurons, resulting in a rapid return of the relay cell to its resting membrane potential to permit high frequency following of the afferent input. In contrast, $85 \%$ of spinal projections to VPLc, primarily transmitting information perceived by the cortex as noxious, lack interactions with GABA-ir interneurons, and form simple axodendritic synapses upon thalamocortical relay cells. The relative lack of GABAergic modulation of the STT information would presumably result in the transmission of a different type of thalamocortical signal by neurons activated by STT, com-

Figure 12. Labeled STT terminals in VPLc contact a relay cell dendrite $(D)$. Solid arrows point to HRP reaction product. Open arrows indicate synaptic contacts. All terminals contacting this segment of dendrite were labeled after WGA-HRP injections into the spinal cord. Scale bar, $1 \mu \mathrm{m}$.

Figure 13. Serial electron micrographs (in photomontage) of a longitudinal section of a relay cell dendrite $(D)$ at a branch point. In $a$, the $a r r o w h e a d$ indicates a dendritic spine. This is shown in the three-dimensional reconstruction in Figure 14. Solid arrows point to HRP reaction product. Open arrows indicate synaptic contacts. Not all terminal profiles contained label in this series, which may be attributed to the extent of the spinal cord injection. A presumed presynaptic dendrite is labeled with an asterisk. It does not make contact with the relay cell dendrite in serial sections. Scale bars, $1 \mu \mathrm{m}$ 


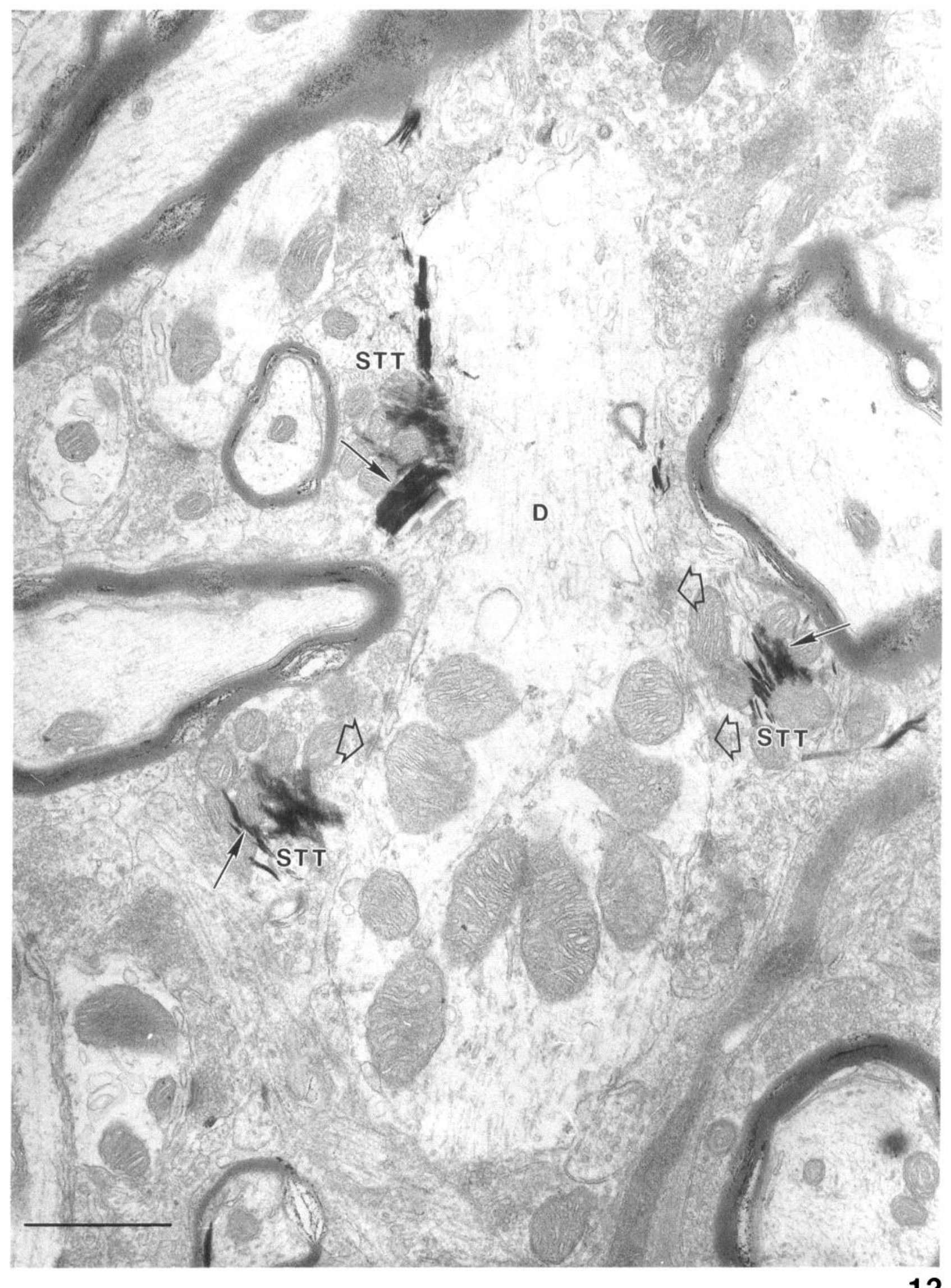



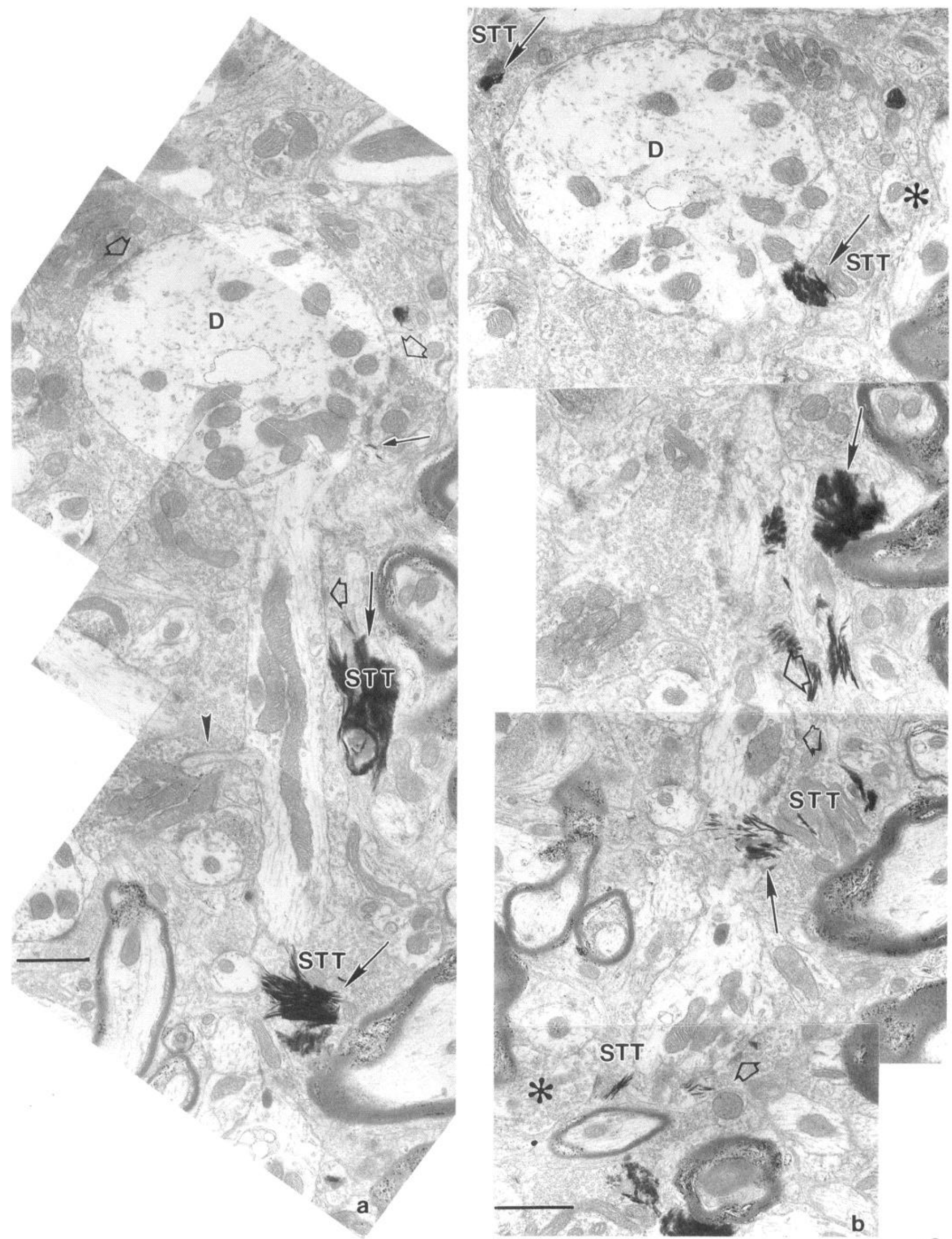

*
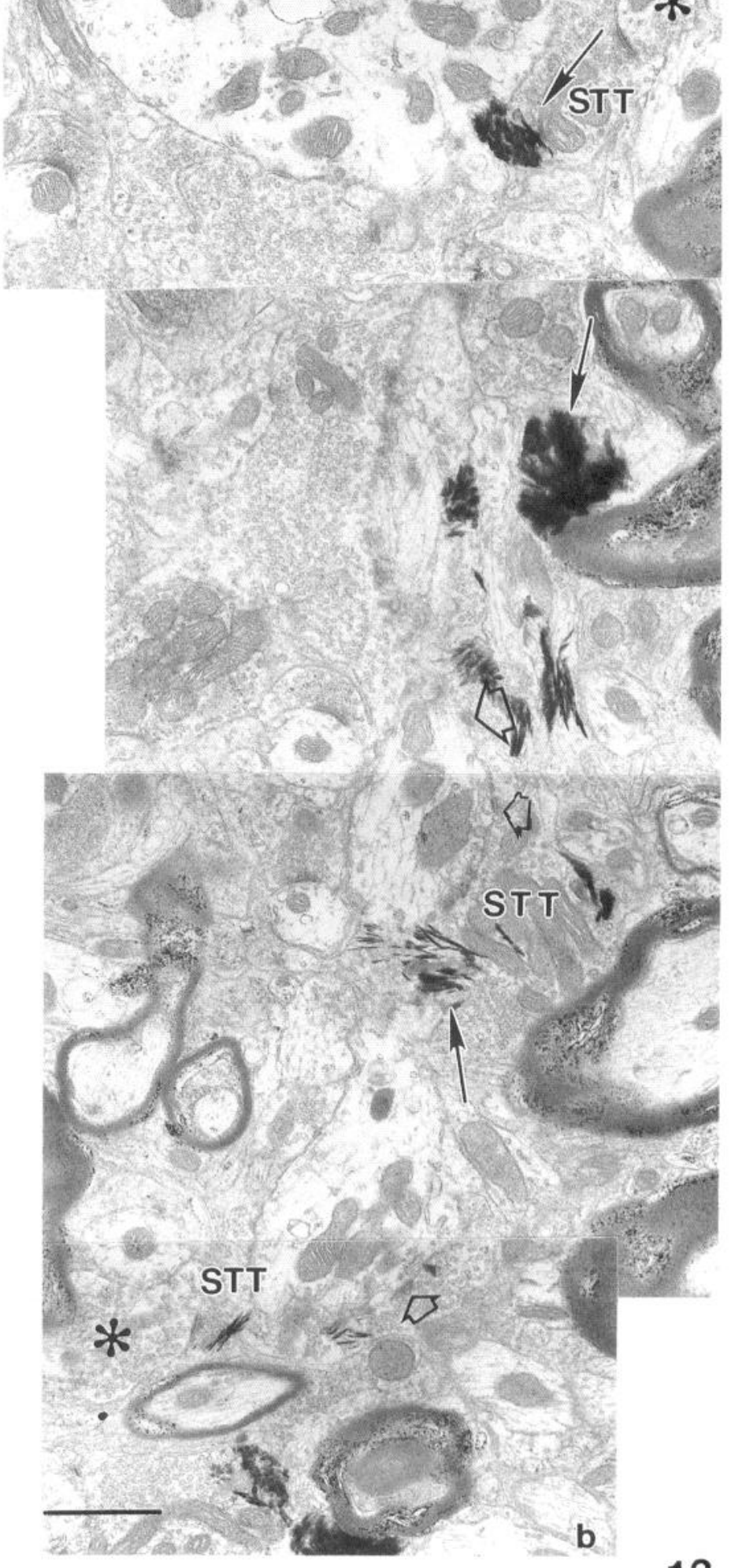

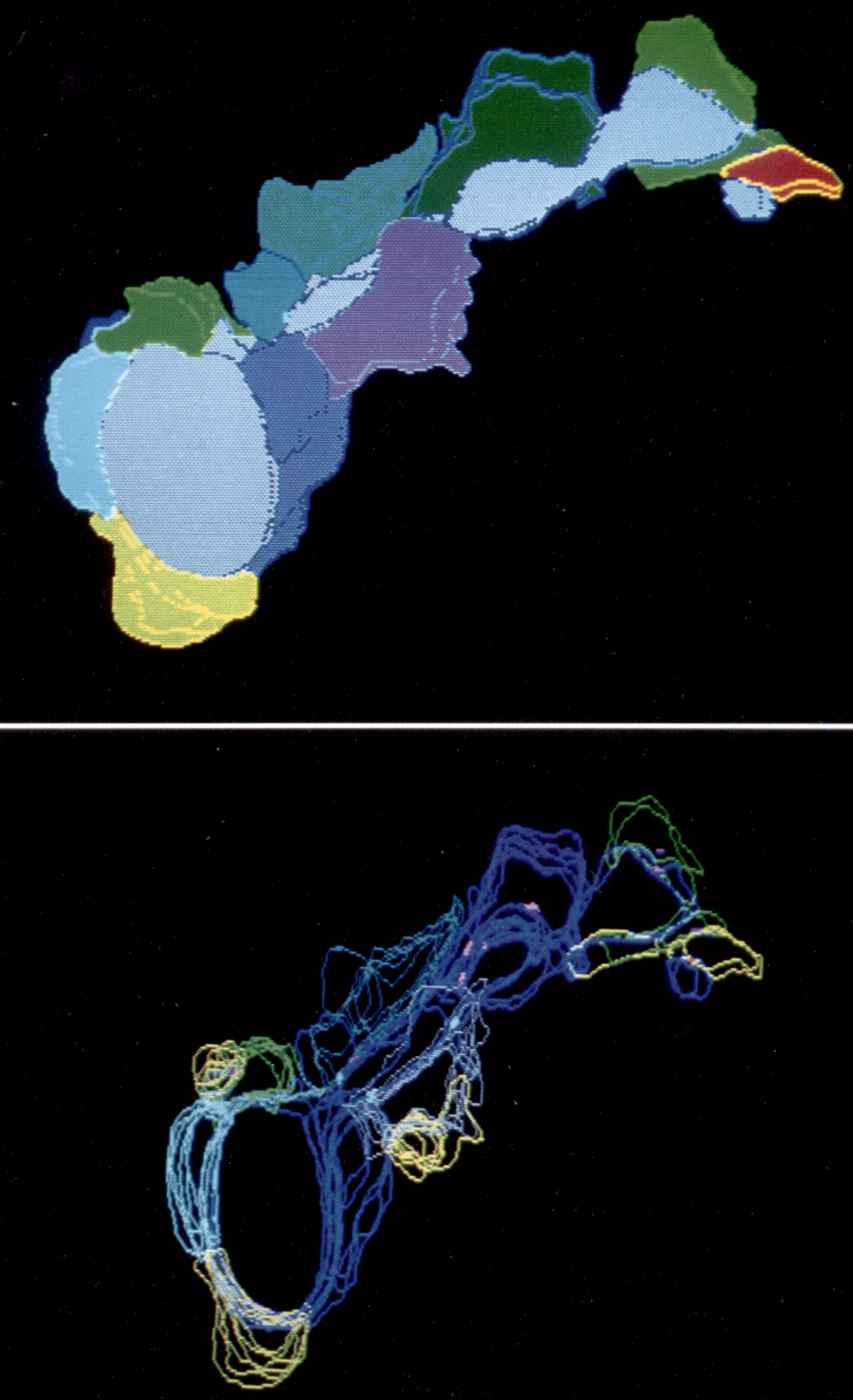

Figure 14. Three-dimensional reconstruction of the profiles shown in Figure 13, $a$ and $b$. $a$, Solid figure reconstruction showing multiple STT terminals contacting the relay cell dendrite (in gray). The red profile at the upper right is a presumed presynaptic dendrite and did not contact the relay cell dendrite. $b$, An outline reconstruction of the same profiles. The contacts made by STT terminals on the relay cell dendrite are shown in pink. 


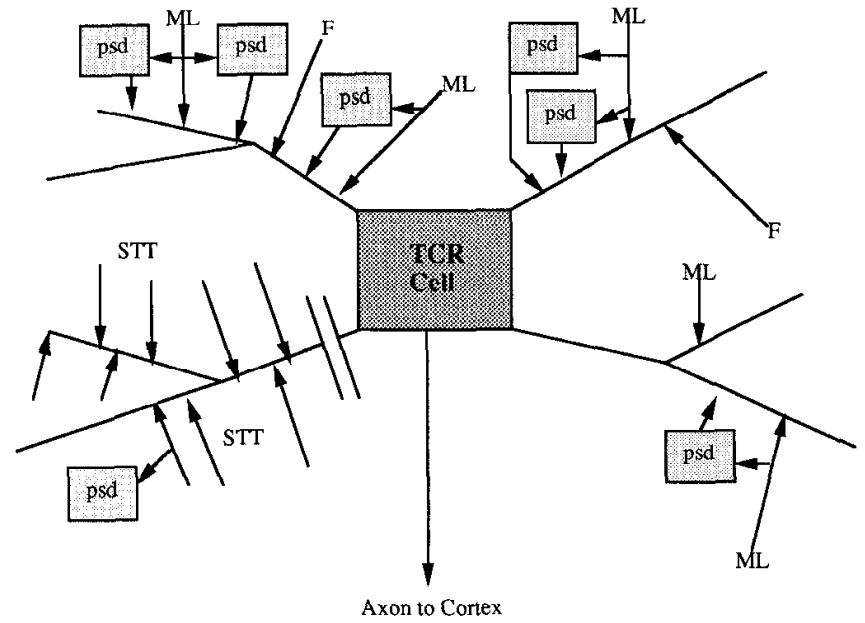

Figure 15. Diagrammatic representation of the principal findings of this study. Thalamocortical relay cells $(T C R$ Cell $)$ in VPLc receive somatosensory projections from the medial lemniscus $(M L)$ and from the spinothalamic tract (STT). A given segment of TCR dendrite receives one or the other afferent, but not both. Most ML afferents also synapse upon one or more vesicle-containing dendritic appendages of GABA-ir interneurons and these dendritic appendages are, in turn, presynaptic [presynaptic dendrite $(p s d)$ ] to the relay cell. The TCR dendritic segment that receives $M L$ and psd synapses also receives synapses from GABA-ir axons $(F)$, which might arise from the thalamic reticular nucleus or from interneurons. STT afferents typically form multiple axonal terminations with a segment of TCR dendrite and seldom contact GABAir presynaptic dendrites. The TCR dendritic segments receiving STT projections are rarely contacted by $\mathrm{F}$ axons. The break in the dendrite receiving STT inputs is to indicate that convergent input from the two afferent systems onto single TCR neurons is yet to be demonstrated.

pared to ML, afferents. Because the majority of spinal afferents carry noxious messages, we propose that it is this information that lacks thalamic GABAergic modulation before being transmitted to the cortex. We suggest that injury to central somatosensory pathways may elicit changes in thalamic GABA synaptic circuitry and GABA receptors to result in non-noxious peripheral stimuli being interpreted by the cortex as noxious, leading to the phenomena of central pain states.

\section{References}

Boivie J (1978) Anatomical observations on the dorsal column nuclei, their thalamic projections and cytoarchitecture of some somatosensory thalamic nuclei in the monkey. J Comp Neurol 178:17-48.

Boivie $J$ (1979) An anatomical reinvestigation of the termination of the spinothalamic tract in the monkey. J Comp Neurol 186:343-370.

Boivie J, Leijon G, Johansson I (1989) Central post-stroke pain: a study of the mechanisms through analyses of the sensory abnormalities. Pain 37:173-185.

Chung JM, Surmeier DJ, Lee KH, Sorkin LS, Tsong Y, Willis WD (1986a) Classification of primate spinothalamic and somatosensory thalamic neurons based on cluster analysis. J Neurophysiol 56:308327.

Chung JM, Lee KH, Surmeier DJ, Sorkin LS, Kim J, Willis WD (1986b) Response characteristics of neurons in the ventral posterior lateral nucleis of the monkey thalamus. J Neurophysiol 56:370-390.

Colonnier M, Guillery RW (1964) Synaptic organization in the lateral geniculate nucleus of the monkey. Z Zellforsch 62:333-355.

Dejerine J, Roussy G (1906) La syndrome thalamique. Rev Neurol 14:521-532.

deZeeuw CI, Holstege JC, Calkoen F, Ruigrok JH, Voogd J (1988) A new combination of WGA-HRP anterograde tracing and GABA immunohistochemistry applied to afferents of the cat inferior olive at the ultrastructural level. Brain Res 447:369-375.

Famiglietti EV, Peters A (1972) The synaptic glomerulus and the intrinsic neuron in the dorsal lateral geniculate nucleus of the cat. J Comp Neurol 144:285-334.

Ferrington DG, Downie JW, Willis WD (1988) Primate nucleus gracilis neurons: responses to innocuous and noxious stimuli. J Neurophysiol 59:886-907.

Guillery RW (1966) A study of Golgi preparations from the dorsal lateral geniculate nucleus of the adult cat. J Comp Neurol 128:2150 .

Guillery RW (1969) The organization of synaptic interconnections in the laminae of the dorsal lateral geniculate of the cat. Z Zellforsch 96: $1-38$.

Hamori J, Pasik P (1983) Differential frequency of P-cells and I-cells in the magnocellular and parvocellular laminae of monkey lateral geniculate nucleus. An ultrastructural study. Exp Brain Res 52:57-66

Hamos JE, Van Horn SC, Raczkowski D, Uhlrich DJ, Sherman SM (1985) Synaptic connectivity of a local circuit neurone in lateral geniculate nucleus of the cat. Nature 317:618-621.

Hendrickson AE, Ogren MP, Vaughn JE, Barber RP, Wu J-Y (1983) Light and electron microscopic immunocytochemical localization of glutamic acid decarboxylase in monkey geniculate complex: evidence for gabaergic neurons and synapses. J Neurosci 3:1245-1262.

Henry MA, Westrum LE, Johnson LR (1985) Enhanced ultrastructural visualization of the horseradish peroxidase tetramethylbenzidine reaction product. J Histochem Cytochem 33:1256-1259.

Jones EG (1985) The thalamus, pp 153-184. New York: Plenum.

Kultas-Ilinsky K, Ilinsky IA (1991) Fine structure of the ventral lateral nucleus (VL) of the Macaca mulatta thalamus: cell types and synaptology. J Comp Neurol 314:319-349.

Le Vay S (1971) On the neurons and synapses of the lateral geniculate nucleus of the monkey, and the effects of eye enucleation. Z Zellforsch 113:396-419.

Ma W, Peschanski M, Ralston HJ III (1987) The differential synaptic organization of the spinal and lemniscal projections to the ventrobasal complex of the rat thalamus. Evidence for convergence of the two systems upon single thalamic neurons. Neuroscience 22:925-934.

McCormick DA (1992) Neurotransmitter actions in the thalamus and cerebral cortex and their role in neuromodulation of thalamocortical activity. Prog Neurobiol 39:337-388.

Mehler WR (1962) The anatomy of the so-called "pain tract" in man: an analysis of the course and distribution of the ascending fibers of the fasciculus anterolateralis. In: Basic research in paraplegia (French J D, Porter RW, eds), pp 26-55. Springfield, IL: Thomas.

Mesulam M-M (1978) Tetramethyl benzidine for horseradish peroxidase neurohistochemistry: a non-carcinogenic blue reaction product with superior sensitivity for visualizing neural afferents and efferents. J Histochem Cytochem 26:106-117.

Ohara PT, Havton L (1993) Quantitative analyses of intracellularly characterized and labeled thalamocortical projection neurons in the ventrobasal complex of primates. J Comp Neurol 336:135-150.

Ohara PT, Lieberman AR, Hunt SP, Wu J-Y (1983) Neural elements containing glutamic acid decarboxylase (GAD) in the dorsal lateral geniculate nucleus of the rat: immunohistochemical studies by light and electron microscopy. Neuroscience 8:189-211.

Ohara PT, Ralston HJ III, Ralston DD (1987) The morphology of neurons and synapses in the somatosensory thalamus of the cat and monkey. In: Thalamus and pain (Besson J-M, Guilbaud G, Peschanski M, eds), pp 171-184. Amsterdam: Elsevier.

Ohara PT, Chazal G, Ralston HJ III (1989) Ultrastructural analysis of GABA-immunoreactive elements in the monkey thalamic ventrobasal complex. J Comp Neurol 283:542-558.

Olszewski J (1952)The thalamus of the Macaca mulatta. Karger: Basel.

Olucha F, Martinez-Garcia F, Lopez-Garcia C (1985) A new stabilizing agent for the tetramethyl benzidine (TMB) reaction product in the histochemical detection of horseradish peroxidase (HRP). J Neurosci 13:131-138.

Paré D, Dossi RC, Steriade M (1991) Three types of inhibitory postsynaptic potentials generated by interneurons in the anterior thalamic complex of cat. J Neurophysiol 66:1190-1204.

Peschanski M, Ralston HJ III (1985) Light and electron microscopic evidence of transneuronal labeling with WGA-HRP to trace somatosensory pathways to the thalamus. J Comp Neurol 236:29-41.

Peschanski M, Ralston HJ III, Roudier F (1983) Reticularis thalami afferent to the VB complex of the rat thalamus. An EM study. Brain Res 270:325-329.

Ralston DD, Milroy AM (1992) Inhibitory synaptic input to identified rubrospinal neurons in Macaca fascicularis: an electron microscopic 
study using a combined immuno-GABA-gold technique and the retrograde transport of WGA-HRP. J Comp Neurol 320:97-109.

Ralston HJ III (1969) The synaptic organization of lemniscal projections to the ventrobasal thalamus of the cat. Brain Res 14:99-116.

Ralston HJ III (1971) Evidence for presynaptic dendrites and a proposal for their mechanism of action. Nature 230:585-587.

Ralston H. III (1983) The synaptic organization of the ventrobasal thalamus in the rat, cat and monkey. In: Somatosensory integration in the thalamus (Macchi G, Rustioni A, Spreafico R, eds), pp 241251. Amsterdam: Elsevier.

Ralston HJ III (1984) Synaptic organization of spinothalamic tract projections to the thalamus, with special reference to pain. In: Advances in pain resources and therapy, Vol 6 (Kruger L, Liebskind JC, eds). New York: Raven.

Ralston HJ III (1991) Local circuitry of the somatosensory thalamus in the processing of sensory information. Prog Brain Res 87:13-28.

Ralston HJ III, Herman MM (1969) The fine structure of neurons and synapses in the ventrobasal thalamus of the cat. Brain Res 14: 77-97.

Ralston HJ III, Ralston DD (1987) Experimentally induced degeneration in the primate ventrobasal thalamus. In: Effects of injury on trigeminal and spinal somatosensory systems (Pubols LM, Sessle BJ, eds), pp 321-330. New York: Liss.

Ralston HJ III, Ralston DD (1992) The primate dorsal spinothalamic tract: evidence for a specific termination in the posterior nuclei ( $\mathrm{Po}$ / SG) of the thalamus. Pain 48:107-118.

Rapisardi SC, Miles TP (1984) Synaptology of retinal terminals in the dorsal lateral geniculate nucleus of the cat. 223:515-534.

Rausell E, Bae CS, Viñuela A, Huntley GW, Jones EG (1992a) Calbindin and parvalbumin cells in monkey VPL thalamic nucleus: distribution, laminar cortical projections, and relations to spinothalamic terminations. J Neurosci 12:4088-4111.

Rausell E, Cusick CG, Taub E, Jones EG (1992b) Chronic deaffer- entation in monkeys differentially affects nociceptive and nonnociceptive pathways distinguished by specific calcium-binding proteins and down-regulates gamma-aminobutyric acid type A receptors at thalamic levels. Proc Natl Acad Sci USA 89:2571-2575.

Roberts WA, Eaton SA, Salt TE (1992) Widely distributed GABAmediated afferent inhibition processes within the ventrobasal thalamus of rat and their possible relevance to patholngical pain states and somatotopic plasticity. Exp Brain Res 89:363-372

Robertson B, Grant G (1985) A comparison between wheat germ agglutinin-and choleragenoid-horseradish peroxidase as anterogradely transported markers in central branches of primary sensory neurones in the rat with some observations in the cat. Neuroscience 14: 895-905.

Spreafico R, Schmechel DE, Ellis LC Jr, Rustioni A (1983) Cortical relay neurons and interneurons in the nucleus ventralis posterolateralis of cats: a horseradish peroxidase, electron-microscopic, Golgi and immunocytochemical study. Neuroscience 9:491-509.

Szentagothai J, Hamori J, Tömböl T (1966) Degeneration and electron microscope analysis of the synaptic glomeruli in the lateral geniculate body. Exp Brain Res 2:283-301.

Tömböl T (1969) Two types of short axon (Golgi 2nd) interneurons in the specific thalamic nuclei. Acta Morphol Acad Sci Hung 17:285297.

Willis WD, Coggeshall RE (1991) Sensory mechanisms of the spinal cord, pp 245-306. New York: Plenum.

Wilson JR (1989) Synaptic organization of individual neurons in the macaque lateral geniculate nucleus. J Neurosci 9:2931-2953.

Wilson JR, Friedlander MJ, Sherman SM (1984) Fine structural morphology of identified $\mathrm{X}$ - and $\mathrm{Y}$-cells in the cat's lateral geniculate nucleus. Proc R Soc Lond [Biol] 221:41 1-436.

Yen C-T, Conley M, Jones EG (1985) Morphological and functional types of neurons in cat ventral posterior thalamic nucleus. J Neurosci 5:1316-1338. 